FEDERAL RESERVE BANK OF SAN FRANCISCO

WORKING PAPER SERIES

\title{
Monetary and Macroprudential Policy in a Leveraged Economy
}

\author{
Sylvain Leduc \\ Federal Reserve Bank of San Francisco \\ Jean-Marc Natal \\ Swiss National Bank
}

April 2015

Working Paper 2011-15

http://www.frbsf.org/publications/economics/papers/2011/wp11-15bk.pdf

\begin{abstract}
Suggested citation:
Leduc, Sylvain and Jen-Marc Natal. 2015. "Monetary and Macroprudential Policy in a Leveraged Economy.” Federal Reserve Bank of San Francisco Working Paper 2011-15. http://www.frbsf.org/economicresearch/publications/working-papers/wp11-15bk.pdf

The views in this paper are solely the responsibility of the authors and do not necessarily reflect the views of the International Monetary Fund, its Executive Board, or IMF management, the Federal Reserve Bank of San Francisco or the Board of Governors of the Federal Reserve System.
\end{abstract}




\title{
Monetary and Macroprudential Policy in a Leveraged Economy *
}

\author{
Sylvain Leduc ${ }^{\dagger}$ and Jean-Marc Natal ${ }^{\ddagger}$
}

April 2015

\begin{abstract}
We examine the optimal monetary policy in the presence of endogenous feedback loops between asset prices and economic activity. We reconsider this issue in the context of the financial accelerator model and when macroprudential policies can be pursued. Absent macroprudential policy, we first show that the optimal monetary policy leans considerably against movements in asset prices and risk premia. We show that the optimal policy can be closely approximated and implemented using a speed-limit rule that places a substantial weight on the growth of financial variables. An endogenous feedback loop is crucial for this result, and price stability is otherwise quasi-optimal. Similarly, introducing a simple macroprudential rule that links reserve requirements to credit growth dampens the endogenous feedback loop, leading the optimal monetary policy to focus on price stability.
\end{abstract}

Keywords: Monetary Policy, asset prices, risk premia, price stability

JEL codes: E52,E58,E32,E44

${ }^{*}$ The views expressed in this paper are those of the authors and do not necessarily represent the views of the International Monetary Fund, its Executive Board, or IMF management, the Federal Reserve Bank of San Francisco, or any other person associated with the Federal Reserve System.

${ }^{\dagger}$ Federal Reserve Bank of San Francisco. Corresponding Author: Sylvain Leduc, Telephone 415-974-3059, Fax 415-974-2168. Email address: sylvain.leduc@sf.frb.org

${ }_{\ddagger}^{\ddagger}$ International Monetary Fund. Email address: JNatal@imf.org 


\section{Introduction}

The financial crisis of 2007-2009 has led to a reconsideration of the role of financial stability in the conduct of monetary policy. In particular, the crisis reignited the view that central banks' focus on inflation targeting may be insufficient to bring about macroeconomic stability and may need to be complemented with targets for some financial measures such as credit, leverage, or asset prices. Indeed, many policymakers have acknowledged that the financial crisis has led them to adjust their views on the role of asset prices in the conduct of monetary policy. ${ }^{1}$

Nevertheless, in keeping with Tinbergen's principle of allocating one instrument per target, the generally preferred approach to tackling financial stability remains to use policy instruments specifically designed for the task, such as micro- or macroprudential policies, and let monetary policy focus on the stabilization of inflation and output gaps. ${ }^{2}$ Yet, this first-best strategy may come with important limitations. As Stein $(2013,2014)$ emphasized, it is unlikely that macroprudential policies by themselves can perfectly contain an unwarranted rise in leverage and credit risk in the economy, partly because macroprudential tools may be difficult to adjust on a timely basis and partly because they don't affect all parts of the financial system equally. In contrast, monetary policy does affect all parts of the financial system (i.e., "it gets in all of the cracks") through changes in interest rates and thus the cost of leverage. In this second-best world, monetary policy could be considered a valuable alternative.

In this paper, we reconsider the role of financial variables in the implementation of monetary policy in the presence of endogenous feedback loops between asset prices, firms' financial health, and overall economic activity, using the financial accelerator model of Bernanke, Gertler, and Gilchrist (1999, BGG). In this framework, entrepreneurs need external sources of funds to finance investment and their level of net worth affects their cost of capital. By directly affecting entrepreneurs' net worth, swings in asset prices affect the cost of credit financing and tend to amplify movements in investment. In contrast to the work of Bernanke and Gertler $(1999,2001)$ and Gilchrist and Leahy (2002), who focused on simple interest rate rules, we emphasize the

\footnotetext{
${ }^{1}$ See, for instance, Yellen (2009) who argues that circumstances may develop where it might be appropriate to lean against booming asset prices with tighter monetary policy.

${ }^{2}$ See Bernanke (2012) among others.
} 
design of optimal policy under commitment and study its impact on asset prices and risk premia (external finance premium, in the words of BGG). To emphasize the issue raised by Stein, we first assume that macroprudential policies are unavailable to policymakers but that they may instead rely on monetary policy to address financial stability issues. ${ }^{3}$ We then introduce macroprudential policy and examine how the optimal policy prescription is affected.

We first show that when macroprudential policy is unavailable, the optimal monetary policy deviates significantly from perfect price stability - the canonical New Keynesian benchmark - and instead leans considerably against movements in financial variables, such as asset prices, leverage, risk premia, or credit growth. This reflects the fact that the tightness of firms' financial constraints varies with the state of the business cycle (a central feature of the financial accelerator), and that, as a result, so does the degree of inefficiency of natural output, i.e., the level of output that ensures perfect price stability. In this context, perfect price stability is suboptimal. Policymakers lean against swings in financial variables (asset prices, leverage, and risk premia) because doing so reduces inefficient fluctuations in output. Hence, optimal policy trades off volatility in the inflation rate for a more efficient allocation of production. In addition to productivity shocks, we experiment with risk shocks, which have been emphasized in the literature as an important driver of the business cycle (see Christiano et al., 2014). We show that the trade-off is more acute when the economy is hit by risk shocks.

Fundamentally, optimal policy leans against movements in financial variables because the feedback loop gives rise to a pecuniary externality. ${ }^{4}$ Entrepreneurs do not internalize the effect of their borrowing behavior on the price of capital and thus on their ability to borrow. For instance, when entrepreneurs as a group borrow more to buy capital goods, the price of capital is bid up. Since net worth is positively related to the price of capital, entrepreneurs' net worth rises, as does their ability to borrow. Because this externality is not internalized by each individual entrepreneurs, it ultimately leads to overborrowing and inefficient movements in output.

A second result of the paper is to show that optimal policy can be closely approximated

\footnotetext{
${ }^{3}$ Curdia and Woodford (2009) and Woodford (2012), for instance, adopt a similar strategy.

${ }^{4}$ Christiano and Ikeda (2011) discuss the pecuniary externality in the BGG model.
} 
by simple "speed-limit" interest rate rules that place a considerable weight on the growth of financial variables in response to real or financial shocks. These rules have the advantage of relying solely on observables. They are also relatively easy to implement as they do not require undue knowledge about the efficient levels of variables, which are typically difficult to assess, particularly in the case of financial variables. ${ }^{5}$ We consider a rule that includes the change in the external finance premium, but our results would be similar if we included alternative measures such as the changes in equity prices, net worth, the leverage ratio, risk premia, or credit as an indicator of financial pressure (see, e.g., Stein, 2014 for an emphasis on risk premia). Broadly speaking, we find that the optimized interest rate rule (the one that best approximates the allocation under optimal policy) is one that puts substantial weight on inflation and the growth of financial variables. ${ }^{6}$

While the suboptimality of perfect price stability policy may be seen as intuitive given the presence of financial frictions, we show that it hinges on two aspects of the model. First, it crucially rests on the presence of an endogenous feedback loop between asset prices and investment - the so-called financial accelerator. When we eliminate the fluctuations in asset prices by allowing capital to adjust at no cost, we find that the optimal policy closely follows the standard prescription to stabilize prices, even in the presence of agency costs. Only when financial fluctuations are significant enough to lead to substantial inefficiency in the equilibrium allocation does optimal policy mitigate movements in asset prices and other financial variables. This result points to the importance of incorporating costly capital accumulation in the model to generate potentially large endogenous movements in asset prices and net worth.

Second, the optimal monetary policy leans against movements in asset prices only when the financial friction interacts with the monopolistic distortion in steady state. With a positive steady-state markup, the inefficient movements in economic activity arising from the presence of agency costs get amplified (for standard nonlinear utility), and the optimal policy trades

\footnotetext{
${ }^{5}$ Interest rate rules including a change in asset prices have also been studied by Gilchrist and Saito (2008) in a model with imperfect information, and by Tetlow (2006) under model uncertainty.

${ }^{6}$ Examining alternative monetary policy rules in the BBG framework in response to financial shocks, Gilchrist and Zakrajšek (2012) also find that placing some weight on the external finance premium in a Taylor-type rule brings about stabilization benefits.
} 
off price stability for a more efficient output allocation by leaning against movements in asset prices and mitigating the effects of the financial accelerator and the associated externality. When we instead allow for a subsidy that eliminates the positive steady-state markup, as is often assumed in the literature, we find that the optimal monetary policy is essentially price stability. Hence a meaningful role for asset prices in the design of optimal monetary policy emerges only in economies in which the natural and efficient allocations differ markedly.

In the last part of the paper, we introduce macroprudential policy and examine its effect on the optimal monetary policy response to productivity and financial shocks. The design of macroprudential policies has attracted a lot of attention recently, and many different policies have been proposed in the literature such as reserve requirements, capital requirements, limits on the loan-to-value ratio, and dynamic provisioning, to name only a few. Here we focus on a countercyclical macroprudential rule that links reserve requirements-a natural instrument in our theoretical environment--to the growth rate of credit in the economy. ${ }^{7}$ Credit growth is a logical focal point for a macroprudential rule given the role of credit in amplifying financial imbalances in periods leading up to financial crises (see Taylor and Schularick, 2012). Policymakers have also been stressing credit growth as a key indicator of financial excess. For instance, the Basel III accord suggests an additional countercyclical capital buffer in periods of above average credit growth.

In addition, countercyclical reserve requirements have often been used in developing economies faced with large financial fluctuations (Federico, Vegh, and Vuletin, 2012) and may be relevant for industrial countries that desire to develop macroprudential tools. ${ }^{8}$ Along those lines, Kayshap and Stein (2012) argued for the use of time-varying reserve requirements on short-term debts to act as a Pigouvian tax on financial institutions engaged in maturity transformation. That said, the gist our results should apply more generally to other types of macroprudential policy that limit credit growth.

\footnotetext{
${ }^{7}$ We follow Claessens et al. (2014), among others, and classify reserve requirements under the rubric of macroprudential policies.

${ }^{8}$ Using a large dataset of banks in advanced and emerging markets economies, Claessens et al. (2014) show that macroprudential policies that limit banks' assets and liabilities, such as reserve requirements, are also effective in limiting credit growth.
} 
When our simple macroprudential rule is calibrated to maximize household welfare, bringing about reserve requirements that vary positively with credit growth, we show that the optimal monetary policy is akin to ensuring perfect price stability since the macroprudential rule dampens the endogenous feedback loop. As credit expands, for instance following an output boom, reserve requirements increase, dampening the associated increase in asset prices and excessive rise in investment. In this case, the optimal monetary policy can be approximated by an interest rate feedback rule that solely reacts to movements in the inflation rate and nearly stabilizes prices.

Overall, macroprudential and monetary policy largely operate as substitutes in our environment: a tighter (looser) macroprudential policy brings about a looser (tighter) optimal monetary policy. Our results suggest that even relatively simple rules can go a long way in reining in the financial accelerator so that monetary policy can focus optimally on price stability. This is particularly the case when the economy is subject to financial shocks.

The remainder of this paper is organized as follows. Before presenting the main building blocks of our model in section 2, we briefly review the relevant literature and stress the value added of our analysis relative to previous contributions. We describe the model's calibration before presenting our main results in section 3, emphasizing the importance of endogenous fluctuations in asset prices. We then discuss a simple and implementable speed-limit rule that closely approximates the optimal monetary policy and conduct a robustness analysis. Finally, we examine the introduction of a simple macroprudential policy that positively links reserve requirements to credit growth and study its implication for the optimal monetary policy.

\subsection{Related literature}

To better emphasize the importance of endogenous feedback loops for monetary policy, we deliberately relied on a standard model and a standard calibration. In addition to being simple, this approach has the added benefit of clarifying the paper's contribution relative to the previous literature. In particular, by modeling endogenous feedback loops through capital accumulation, our analysis of optimal policy complements the recent contributions of Curdia and Woodford 
(2009), Woodford (2012), and particularly those of De Fiore and Tristani (2013), De Fiore, Teles, and Tristani (2011) and Carlstrom, Fuerst, and Paustian (2010). De Fiore and Tristani (2013) study the optimal monetary policy in a model with costly state verification and price rigidity, but one in which there are no endogenous movements in net worth, partly reflecting the absence of capital accumulation. They derive the loss function of the central bank, which they show to depend on the volatility of the nominal interest rate and credit spreads, in addition to the volatility of inflation and that of the output gap. They find that following a financial shock, interest rates should be aggressively lowered but price stability remains nearly optimal otherwise.

In contrast, Carlstrom, Fuerst, and Paustian (2010) derive the optimal monetary policy in an environment in which firms' labor hiring is constrained by their net worth, as in the model of Kiyotaki and Moore (1997). They show that the central bank's loss function is partly a function of the tightness of the credit constraint, which they interpret as a risk premium. Although their model abstracts from capital accumulation, it captures endogenous movements in net worth through movements in share prices of monopolistic sticky-price firms. They show that stabilizing inflation is nearly optimal in their framework, even if the credit constraint is quite severe, because the weight on inflation volatility in the central bank's loss function dwarfs that on the variability of the risk premium.

De Fiore, Teles, and Tristani (2011) also examine the optimal monetary policy in a model with agency costs in which firms' financing conditions are predetermined. They show that the optimal policy allows deviations from price stability to mitigate output fluctuations via movements in firms' real funds needed to finance production.

One important distinguishing feature of our work is the introduction of capital accumulation, which allows us to directly examine the importance of the financial accelerator for the design of optimal monetary policy. This additional feature allows an endogenous feedback between asset prices, net worth, and economic activity, which implies that the optimal monetary policy should lean against movements in financial variables,bringing about departures from perfect price stability. Absent this mechanism, price stability is quasi-optimal. 
Our paper also relates to Faia and Monacelli (2007), who study the design of optimized interest rate rules in response to technology and government spending shocks in a model with agency costs adapted from the work of Carlstrom and Fuerst (1997). Faia and Monacelli find that the optimal rule remains focused on stabilizing inflation. One important difference between our analysis and theirs is that we explicitly consider a model where the efficient and natural output differ markedly. We also complement their analysis by emphasizing the design of optimal policies under financial shocks and by considering speed-limit rules as implementable policy rules.

Finally, we add to this body of work by considering the impact of simple macroprudential rules on the optimal monetary policy. In so doing, our paper also complements a growing body of work that examines the effects of different macroprudential policies on the economy (see Christensen, Meh, and Moran (2011), Angeloni and Faia (2013), and Quint and Rabanal (2013), among others). To keep our analysis tractable we abstracted from modeling the strategic interactions between monetary and macroprudential policies. However, benefits can arise from policy coordination (on this issue see, for instance, Beau, Clerc, and Mojon (2011), Collard et al. (2012) and Angelini, Neri, and Panetta (2014)).

\section{The model}

Our analysis draws on BGG's seminal work and on the more recent contributions of Christiano, Motto, and Rostagno (CMR (2003, 2010, 2014)). The economy consists of four sectors. The first two sectors produce intermediate and final goods, respectively, while the third produces physical capital and the fourth provides loans to investors and can be interpreted as a pseudobanking sector. Banks in our framework are risk-averse and hold a perfectly diversified portfolio of entrepreneurial loans. The economy is populated by households composed of consumers and workers and by risk-neutral entrepreneurs. The latter own the capital stock and provide capital services to intermediate goods producers. Entrepreneurs finance their purchases of capital both with internal funds (own net worth) and external funds (bank loans). Entrepreneurs face idiosyncratic productivity shocks and are subject to bankruptcy if their project fails. The 
banking sector receives deposits from households (which are considered riskless and are thus remunerated as such) and make loans to entrepreneurs. A key mechanism of the model is that the premium over the risk-free rate - the so-called external finance premium - that entrepreneurs must pay to borrow is related to their leverage. The more "skin in the game" the entrepreneurs have, the smaller is the moral hazard problem and the premium.

In the following, we describe the main building blocks of the model, which features a traditional New Keynesian model augmented by a financial accelerator following BGG and CMR. More details can be found in the appendix.

\subsection{Main building blocks}

\subsubsection{Capital producers}

As in CMR (2010,2014), there is a large number of identical capital producers operating under perfect competition who, at time $t$, produce new physical capital $k_{t+1}$ to be used in $t+1$, using the following production function:

$$
k_{t+1}=(1-\delta) k_{t}+\left(1-S\left(i_{t} / i_{t-1}\right)\right) i_{t},
$$

where $i_{t}$ denotes investment, $\delta$ is the depreciation rate $0 \leq \delta \leq 1$ and $S(\cdot)$ is an increasing and convex function. The new capital stock is sold at price $Q_{t}$ and the old capital stock is purchased at price $\widetilde{Q}_{t}$ on the capital market. Therefore, profits are given by

$$
\Pi_{t}^{k}=Q_{t} k_{t+1}-P_{t} i_{t}-\widetilde{Q}_{t} k_{t}
$$

Maximizing profit subject to the production constraint leads to the following two firstorder conditions:

$$
\begin{aligned}
& Q_{t}\left(\left(1-S\left(i_{t} / i_{t-1}\right)\right)-S^{\prime}\left(i_{t} / i_{t-1}\right) i_{t} / i_{t-1}\right)=P_{t} \\
& \widetilde{Q}_{t}=Q_{t}(1-\delta) .
\end{aligned}
$$




\subsubsection{Entrepreneurs}

There is a large number of heterogeneous entrepreneurs, indexed by $j$, who buy new capital stock $k_{j, t+1}$ at price $Q_{t}$ from the capital producers and transform it into capital services $x_{j, t+1}$ according to the linear technology:

$$
x_{j, t+1}=\omega_{j} k_{j, t+1},
$$

where $\omega_{j}$ denotes the productivity of the transformation technology which is entrepreneurspecific. The random variable $\omega$ is drawn from a cumulative distribution denoted by $F_{t}\left(\omega^{\star}\right)=$ $P\left(\omega_{j} \leqslant \omega^{\star}\right)$ with mean $E(\omega)=1$. Entrepreneurial investment is risky and, as in CMR, the degree of risk is assumed to vary over time. Therefore we assume that $\log (\omega)$ is normally distributed with mean $\mu_{\omega, t}$ and standard deviation $\sigma_{\omega, t}$. The standard deviation $\sigma_{\omega, t}$ is the realization of a mean-preserving stochastic process referred to below as a "risk shock," which follows an $\operatorname{AR}(1)$ process with autoregressive coefficient $\rho_{\sigma_{\omega}}$ and innovations, $\varepsilon_{\sigma_{\omega}}$, assumed to be normally distributed with mean zero and standard deviation $\sigma_{\varepsilon_{\sigma_{\omega}}}$.

Each entrepreneur draws its type $\omega_{j}$ after capital $k_{j, t+1}$ has been purchased. To purchase capital, each entrepreneur can either use her net worth $N_{j, t+1}$ or borrow $B_{j, t+1}$ from banks at the gross rate of interest $R_{j, t+1}^{b}$. To ensure that entrepreneurs do not accumulate enough net worth to make the borrowing constraint nonbinding, we assume that entrepreneurs exit the economy (close business) each period with probability $1-\gamma \cdot{ }^{9}$ Within each period, entrepreneurs rent their capital services to intermediate goods producers at the real price $z_{t+1}$, and at the end of the period they resell their capital stock to capital producers at price $\widetilde{Q}_{t+1}$.

Hence, entrepreneur $j$ 's expected revenue from purchasing capital can be written as

$$
E_{t}\left[P_{t+1} z_{t+1} \omega_{j} k_{j, t+1}+\widetilde{Q}_{t+1} \omega_{j} k_{j, t+1}\right] .
$$

Denoting the rate of return on capital as

$$
R_{t+1}^{k} \equiv \frac{P_{t+1} z_{t+1}+\widetilde{Q}_{t+1}}{Q_{t}},
$$

\footnotetext{
${ }^{9}$ To maintain a constant population of entrepreneurs, we assume that $1-\gamma$ new entrepreneurs are born at the same time. These entrepreneurs finance their purchases with a transfer, $\tau_{t}^{e}$, that they receive from the government. Departing entrepreneurs consume their net worth.
} 
we can rewrite an entrepreneur's expected revenue in the following way

$$
E_{t}\left[Q_{t} R_{t+1}^{k} \omega_{j} k_{j, t+1}\right]
$$

To finance capital purchases, the entrepreneur can either use her net worth $N_{j, t+1}$ or enter a contract with a bank to borrow $B_{j, t+1}$ at gross rate $R_{j, t+1}^{b}$, such that

$$
Q_{t} k_{j, t+1}=N_{j, t+1}+B_{j, t+1}
$$

The debt contract then specifies the loan amount $B_{j, t+1}$ and the nominal gross rate $R_{j, t+1}^{b}$. If the entrepreneur's project is a success she pays back the loan and interest $\left(R_{j, t+1}^{b} B_{j, t+1}\right)$ to the bank. If the project fails (because the project's productivity, $\omega_{j}$, turns out to be too low) the bank pays a proportional cost $\mu$ to monitor the entrepreneur and confiscates the remaining assets. Thus, there exists a cutoff value $\omega_{j, t+1}^{\star}$ defined as

$$
R_{j, t+1}^{b} B_{j, t+1}=\omega_{j, t+1}^{\star} Q_{t} R_{t+1}^{k} k_{j, t+1}
$$

below which the entrepreneur declares bankruptcy.

The expression for an entrepreneur's expected profit can be derived to be

$$
E_{t}\left[\int_{\omega_{j, t+1}^{\star}}^{\infty}\left(\omega Q_{t} R_{t+1}^{k} k_{j, t+1}-R_{j, t+1}^{b} B_{j, t+1}\right) \mathrm{d} F(\omega)\right] .
$$

Using the definition of the cutoff value $\omega_{j, t+1}^{\star}$, and making use of the fact that $k_{j, t+1}$ is decided in period $t$, the expected profit function rewrites as

$$
E_{t}\left[\int_{\omega_{j, t+1}^{\star}}^{\infty}\left(\omega-\omega_{j, t+1}^{\star}\right) R_{t+1}^{k} \mathrm{~d} F(\omega)\right] Q_{t} k_{j, t+1},
$$

which defines the entrepreneur's objective function.

\subsubsection{Banks and reserve requirements}

Since the bank receives $R_{j, t+1}^{b} B_{j, t+1}$ if an entrepreneur's productivity is higher than the cutoff value $\omega_{j, t+1}^{\star}$ and otherwise seizes all the entrepreneur's assets $\omega_{j} Q_{t} R_{t+1}^{k} k_{j, t+1}$ if the project fails (after having paid a proportional monitoring cost, $\mu$ ), the bank's revenue corresponds to:

$$
\int_{\omega_{j, t+1}^{\star}}^{\infty} R_{j, t+1}^{b} B_{j, t+1} \mathrm{~d} F(\omega)+(1-\mu) \int_{0}^{\omega_{j, t+1}^{\star}} \omega Q_{t} R_{t+1}^{k} k_{j, t+1} \mathrm{~d} F(\omega)
$$


which can be rewritten as

$$
\left(1-F\left(\omega_{j, t+1}^{\star}\right)\right) R_{j, t+1}^{b} B_{j, t+1}+(1-\mu) \int_{0}^{\omega_{j, t+1}^{\star}} \omega Q_{t} R_{t+1}^{k} k_{j, t+1} \mathrm{~d} F(\omega) .
$$

Banks are assumed to be perfectly competitive and riskless. They finance themselves via household deposits $B_{j, t+1}$ that earn the nominal (risk-free) gross interest rate $R_{t}$, where $R_{t}$ is not contingent on shocks realized in $t+1$.

In addition, banks' lending is subject to macroprudential policy restrictions. In particular, we assume that banks are subject to a reserve requirement, $\phi_{t}$, which varies with indicators of financial activity, $F I_{t}$, (for instance, credit growth, leverage ratio, asset prices, among others) according to a simple rule

$$
\phi_{t}=\phi^{*}+\chi F I_{t}, \quad 0<\phi_{t}<1
$$

where $\phi^{*}$ is a constant and $\chi$ is a parameter calibrated such that $0<\phi_{t}<1$ for reasonable values of $F I_{t}$.

For simplicity, banks' reserves are assumed to be kept in "cash" and earn a zero rate of return. ${ }^{10}$ Given the reserve requirement, $\phi_{t}$, determining the fraction of loanable deposits, the financial intermediary must issue $B_{j, t+1} /\left(1-\phi_{t}\right)$ deposits to finance $B_{j, t+1}$ loans per entrepreneurs. Therefore, the zero profit condition implies

$$
\left(1-F\left(\omega_{j, t+1}^{\star}\right)\right) R_{j, t+1}^{b} B_{j, t+1}+(1-\mu) \int_{0}^{\omega_{j, t+1}^{\star}} \omega Q_{t} R_{t+1}^{k} k_{j, t+1} \mathrm{~d} F(\omega)=R_{t} \frac{B_{j, t+1}}{\left(1-\phi_{t}\right)},
$$

which also corresponds to the bank's participation constraint.

In turn, the contract between a bank and a borrower specifies a level of loans, $B_{j, t+1}$ and a gross interest rate $R_{j, t+1}^{b}$ that maximizes the expected profit of the entrepreneur, subject to the participation constraint of the bank. Equivalently the contract determines a level of capital, $k_{j, t+1}$, and a cutoff point, $\omega_{j, t+1}^{\star}$ by maximizing entrepreneurs' profits, subject to the bank's

\footnotetext{
${ }^{10}$ We could alternatively assume that reserves are remunerated. The key assumption is that the rate of return on reserves should be smaller than the rate $R_{t}$ earned by households on bank deposits such that an increase in reserves leads to an increase in the risk premium, as per the banks' zero profit condition.
} 
participation constraint above. In the appendix, we show that the solution to this problem is given by the following two equations

$$
\begin{gathered}
E_{t}\left[\left[1-\Gamma\left(\omega_{j, t+1}^{\star}\right)\right] R_{t+1}^{k}+\frac{\left.\left[\Gamma\left(\omega_{j, t+1}^{\star}\right)-\mu G\left(\omega_{j, t+1}^{\star}\right)\right] R_{t+1}^{k}-\frac{R_{t}}{\left(1-\phi_{t}\right)}\right]}{1-\mu \omega_{j, t+1}^{\star} h\left(\omega_{j, t+1}^{\star}\right)}=0\right. \\
{\left[\left(\Gamma\left(\omega_{j, t+1}^{\star}\right)\right)-\mu G\left(\omega_{j, t+1}^{\star}\right)\right] Q_{t} R_{t+1}^{k} k_{j, t+1}-R_{t} \frac{\left(Q_{t} k_{j, t+1}-N_{j, t+1}\right)}{\left(1-\phi_{t}\right)}=0 .}
\end{gathered}
$$

Note that the presence of reserve requirements, $\phi_{t}$, affects the contract between the bank and the entrepreneur. In Section 3.6 below, we show that a tighter macroprudential policy captured by a higher reserve requirement, $\phi_{t}$, leads to a higher spread between the risky and riskless rates of return. Intuitively, since part of the bank's source of funds must be held in reserve, it is more costly for the bank to make a loan of a given size, which is reflected in a higher interest rate spread. ${ }^{11}$ Clearly, the standard contract arises in the absence of reserve requirements (i.e., $\phi_{t}=0$, for all $\left.t\right)$.

\subsubsection{Aggregated net worth}

The contract between a bank and an entrepreneur specifies a level of loans, $B_{j, t+1}$, and a gross interest rate, $R_{j, t+1}^{b}$, that maximizes the expected profit of the entrepreneur subject to the bank's participation constraint, or identically a level of capital $k_{j, t+1}$ and a cutoff point $\omega_{j, t+1}^{\star}$. Clearly, the amount of loans and therefore the level of investment will depend on entrepreneurs' net worth $N_{j, t+1}$ (the new state variable associated with asymmetric information). Aggregating over all entrepreneurs, it can be shown (see Appendix and BGG for details) that entrepreneurial net worth evolves according to

$$
N_{t+1}=\gamma \Xi_{t}+\tau_{t}^{e}
$$

where $\Xi_{t}$ is the aggregate profit flow to entrepreneurs, $\tau_{t}^{e}$ is the government transfer to "newly born" entrepreneurs, and $\gamma$ is the entrepreneurs' constant survival probability. ${ }^{12}$

\footnotetext{
${ }^{11}$ Quint and Rabanal (2011) also introduce a macroprudential regulation in a financial accelerator model of a monetary union, which increases the spread faced by borrowers.

${ }^{12}$ In Leduc and Natal (2011), we also examined a shock to net worth, as captured by an innovation to $\gamma_{t}$.
} 


\subsubsection{Intermediate goods producers}

Intermediate goods producers are monopolistically competitive. They produce an intermediate good by means of capital and labor according to a constant return to scale production function:

$$
y_{t}(i)=a_{t} k_{t}(i)^{\alpha} h_{t}(i)^{1-\alpha} \quad \text { with } \alpha \in(0,1),
$$

where $k_{t}(i)$ and $h_{t}(i)$ respectively denote the physical capital and the labor input used by firm $i$ to produce $y_{t}(i)$, and where $a_{t}$ represents total factor productivity, which is assumed to follow an $\operatorname{AR}(1)$ process with autoregressive coefficient $\rho_{a}$ and innovation, $\varepsilon_{a}$, that is normally distributed with mean zero and standard deviation $\sigma_{a}$.

The firm determines its production plan to minimize its total cost :

$$
\min _{\left\{h_{t(i)}, k_{t}(i)\right\}} P_{t} w_{t} h_{t(i)}+P_{t} z_{t} k_{t}(i)
$$

subject to production. As is standard in the New Keynesian literature, we assume that firms set their prices according to Calvo's staggering scheme and define $\tau$ as the probability that a particular firm is able to reset its price next period.

\subsubsection{Final goods producers}

Final goods are produced by competitive retailers that assemble intermediate goods according to a CES aggregator

$$
y_{t}=\left(\int_{0}^{1} y_{t}(i)^{\frac{1}{\lambda}} d i\right)^{\lambda} \quad \text { with } \lambda \in[1, \infty),
$$

where $\lambda$ stands for the elasticity of substitution between intermediate goods and determines the intermediate good producers' market power (or the steady-state markup of price $P$ over their marginal costs).

\subsubsection{Households}

The representative household maximizes the discounted value of its lifetime utility that features preferences over consumption and labor:

$$
\mathcal{U}_{t}=E_{0} \sum_{j=0}^{\infty} \beta^{j}\left(\frac{1}{1-\sigma_{c}} c_{t+j}^{1-\sigma_{c}}-\frac{\nu_{h}}{1+\sigma_{h}} h_{t+j}^{1+\sigma_{h}}\right),
$$


subject to the budget constraint

$$
P_{t} C_{t}=P_{t} w_{t} h_{t}+\Pi_{t}+R_{t-1} B_{t}-B_{t+1},
$$

where $\Pi_{t}$ represents the dividends earned on the profits of intermediate goods firms, $0<\beta<1$ represents the rate of time preference, and $\nu_{h}$ is a normalizing constant.

The household is also subject to the time endowment constraint

$$
l_{t}+h_{t}=1
$$

where $l_{t}$ denotes the proportion of total time dedicated to leisure.

\subsection{Baseline calibration}

The baseline calibration is standard and is reported in Table 1. We assume a coefficient of relative risk aversion, $\sigma_{c}=1.5$ and we set $\sigma_{h}$ to 1 , implying a unit Frisch elasticity of labor supply. We choose $\beta=0.99$, leading to an annual real interest rate of 4 percent.

Because of monopolistic competition and costly state verification (the model's financial friction for $\mu>0$ ), the steady state of the model is distorted. The gross markup of price over marginal costs, $\lambda$, is set to 1.1. The capital share parameter in the Cobb-Douglas production function $\alpha=0.36$, and the quarterly depreciation rate is 2.5 percent per quarter. We assume a Calvo parameter $\theta$ of 0.75 , so that, on average, firms expect to be able to change their price once a year.

We follow BGG (1999), Carlstrom and Fuerst (1997), and CMR (2010), and calibrate

the financial intermediation block to obtain an annual credit risk premium $\left(\frac{R^{k}}{R}\right)$ of about 2 percentage points in the steady state. The entrepreneur's ex ante survival probability (from one quarter to the next), $\gamma$, is set to 97.28 percent, in line with BGG. We set the bank's monitoring cost as a share of final output, $\mu=0.2$ while $F\left(\omega^{\star}\right)$, the proportion of businesses going bankrupt per quarter, is set to 0.75 percent.

Those parameter values imply the economy's steady-state capital-output ratio, $\frac{k}{y}=8.08$ and the investment-output ratio, $\frac{i}{y}=0.2$, broadly in line with estimations provided by CMR (2010) for the euro area $(8.70 ; 0.21)$ and the United States $(6.98 ; 0.25)$. 
We specify the investment adjustment cost function as in CMR (2014):

$$
S\left(x_{t}\right)=\frac{1}{2}\left\{\exp \left[\sqrt{S^{\prime \prime}}\left(x_{t}-x\right)\right]+\exp \left[-\sqrt{S^{\prime \prime}}\left(x_{t}-x\right)\right]-2\right\}
$$

where $x_{t} \equiv i_{t} / i_{t-1}$ and $x$ represents its steady-state value. Note that $S(x)=S^{\prime}(x)=0$ and $S^{\prime \prime}(x)=S^{\prime \prime}$, where $S^{\prime \prime}$ is a model parameter that we calibrate to 10 , based on the estimated value in CMR (2014).

As mentioned previously, our macroprudential policy takes the form of a reserve requirement rule given by equation (7) above and reproduced here for convenience

$$
\phi_{t}=\phi^{*}+\chi F I_{t}, \quad 0<\phi_{t}<1
$$

In the benchmark model, we first abstract from macroprudential policy and set $\phi^{*}=\chi=0$. For the experiments in which we introduce macroprudential policy, we first set $\phi^{*}$ in line with the evidence in Federico, Vegh, and Vuletin (2012) who find that the average reserve requirement in industrialized countries over the period 1975-2011 is 2 percent. We then consider a reserve requirement rule in which the financial indicator is credit growth. We first concentrate on an optimized value of $\chi$. Specifically, we find the value of $\chi$ that maximizes welfare, assuming that monetary policy is set optimally taking into account the macroprudential rule (we describe the way we characterize the optimal monetary policy below). This leads to $\chi=1.0064$, so that reserve requirements vary positively with credit growth (i.e., they are countercyclical). We then compare this rule's implications to one where reserve requirement respond more aggressively to credit growth, setting $\chi=3 .^{13}$

Finally, in all the simulation exercises, we set the parameters $\left(\rho_{a}, \rho_{\sigma_{\omega}}\right.$ and $\left.\sigma_{\varepsilon_{a}}, \sigma_{\varepsilon_{\sigma_{\omega}}}\right)$ of the $\mathrm{AR}(1)$ processes to correspond to the mode of their estimated posterior distribution for the United States in CMR (2014).

\footnotetext{
${ }^{13}$ Assuming that monetary policy pursues strict price stability, for instance, we find an optimal value of $\psi=1.85$.
} 


\section{The results}

We compute the optimal monetary policy under commitment following the timeless perspective approach of Woodford (2003). We do so explicitly by acknowledging the distorted nature of the steady state. That is, competitive inefficiencies are not offset by lump-sum subsidies (see, for instance, Benigno and Woodford, 2005) and monitoring costs are positive in the steady state. We study the responses to shocks to aggregate productivity, $a_{t}$, and to the cross-sectional distribution of entrepreneurs' individual productivity, $\sigma_{\omega}$, and contrast the optimal precommitment policy to the traditional New Keynesian optimal benchmark, which consists of ensuring perfect price stability.

As a useful and simpler benchmark, we first abstract from macroprudential policies, setting $\phi_{t}=0$, for all $t$. Using this benchmark model, we show three main results. First, the presence of a financial accelerator introduces a nontrivial policy trade-off that is especially acute in response to financial shocks. Endogenous fluctuations in net worth triggered by fluctuations in asset prices play an important role in driving resource allocation away from their most efficient use. This is in contrast to a recent literature (e.g., Faia and Monacelli (2007)) that finds that the traditional New Keynesian optimal policy prescription (perfectly stabilizing prices under both real and financial shocks) remains optimal even in the presence of financial frictions.

Second, we show that the large consensus around a policy of perfect price stabilization, even in the presence of a financial accelerator, is due to the standard (and unrealistic) New Keynesian assumption that policymakers can compensate workers for the monopolistic competition distortion in a lump-sum fashion. While the financial friction is a necessary condition for a policy trade-off to arise, the latter remains quantitatively small if the competitive distortion-by far the largest friction in the model-is subsidized away. ${ }^{14}$

Third, to study the importance of asset prices, interest rate spreads, or leverage ratio targeting in the conduct of monetary policy, we simulate the economy under different interest rate rules to which we append these alternative indicators. We show that the optimal precom-

\footnotetext{
${ }^{14}$ In Leduc and Natal (2011), we show that the optimal policy prescription is invariant to whether household bank deposits are protected against surprise inflation (as in BGG 1999) or not (as in CMR 2010).
} 
mitment policy can be closely approximated and implemented using a speed-limit monetary policy rule that places a substantial weight on the growth rate of financial variables.

We then modify this benchmark model by introducing a simple, implementable, macroprudential policy with countercyclical reserve requirements (where reserve requirements increase with credit growth). Introducing this simple rule has a substantial impact on our benchmark result. When the macroprudential policy leans against credit growth, the optimal monetary policy focuses almost exclusively on price stability in response to productivity and financial shocks. Hence, the macroprudential and monetary policies are substitutes: a tighter (looser) macroprudential policy brings about a looser (tighter) optimal monetary policy.

\subsection{Optimal monetary policy}

Following Woodford's (2003) timeless perspective approach, impulse responses under optimal policy refer to an equilibrium where policy is described by the first-order conditions of a Ramsey planner deciding on allocation for $t \geq 1$ and ignoring the potential time inconsistency problem due to the particular nature of $t=0$. Dynare is used to solve for optimal policy.

In the BGG framework, optimal policy is difficult to characterize since, in principle, the social planner has to maximize welfare of two different types of agents, households and entrepreneurs. This is nontrivial since entrepreneurs and households have different degrees of risk aversion (entrepreneurs are risk-neutral) and different discount factors. In BGG, entrepreneurs are assumed to be extremely patient since they are willing to postpone consumption to the period before they die.

Following De Fiore et al. (2011), we do not include the entrepreneurs in the social welfare function because we do not want to think of them as actual agents but as a way to introduce the financial friction in the model. Moreover, because entrepreneurs are risk-neutral, the volatility of the economy under different policies does not affect the entrepreneurs' average level of consumption. Therefore, excluding entrepreneurs from the welfare calculation does not impact the welfare ranking of alternative policies, as it would only introduce a constant in the welfare calculation (see Faia and Monacelli 2007 for a similar argument). 


\subsection{Optimal policy versus perfect price stability (PPS)}

Consider first the impact of a positive and temporary productivity shock when monetary policy either is conducted optimally or targets price stability. ${ }^{15}$ In the financial accelerator model, higher productivity leads to higher asset prices, which increases entrepreneurs' net worth and results in higher investment. In turn, the increase in investment and output stimulates asset prices, which then feed back into higher net worth and investment. Figure 1 shows that optimal policy tends to dampen the response of the economy compared to a policy of perfect price stability (PPS), the canonical New Keynesian benchmark. Compared to PPS, the optimal policy is more restrictive, as shown by the increase in the real interest rate, which initially slows the economy and leads to a decline in inflation. On impact the rise of asset prices under the optimal policy is almost half of that under PPS, which in turn dampens the responses of net worth, leverage, and the risk premium by similar magnitudes. At the same time, optimal policy allows some fluctuations in the inflation rate as policymakers trade off inflation stabilization for output stabilization.

The optimal policy trade-off illustrated in Figure 1 means that there is an externality associated with the financial accelerator mechanism: The financial friction (monitoring cost) gives rise to an overreaction of investment and output with respect to the efficient allocation, which optimal policy takes into account. Figure 2 compares the efficient responses to the responses that would arise under either PPS or the optimal policy following a positive productivity shock. We define the efficient response as that of the economy without financial frictions, in which a lump-sum tax-financed subsidy offsets the monopolistic competition distortion in the steady state and where prices are perfectly flexible. The figure shows that, under the optimal policy the rise in net worth and equity is more muted than under the natural allocation brought about by PPS. Fewer investment projects are financed, which aligns the response of the economy more closely with the efficient allocation where financial frictions are absent.

Although the difference between the optimal monetary policy and a policy that aims at

\footnotetext{
${ }^{15}$ Note that because we assume a non-efficient steady state, the natural allocation ensuring price stability is not necessarily efficient.
} 
PPS remains relatively small following a productivity shock, the departure from price stability becomes much more pronounced when the economy is hit by financial shocks. Because financial shocks interfere directly with the financial intermediation process, they have a more direct bearing on asset prices, net worth, and finance premia than productivity shocks. We examine a drop in $\sigma_{\omega}$, i.e., a decline in the cross-sectional distribution of entrepreneurs' individual productivity, interpreted as a decrease in the perception of market risk, which affects risk premia directly (see CMR (2010)). ${ }^{16}$ As in the case of a productivity shock, the optimal monetary policy leans against movements in asset prices and net worth, but the difference between optimal policy and PPS is somewhat starker. As shown in Figure 3, the optimal policy is more restrictive than PPS - as reflected in the sudden more pronounced tightening of real interest rates - dampening the rise in equity prices and avoiding the increase in net worth that occurs under PPS. By leaning against the jump in asset prices, the optimal policy avoids the investment spree that characterizes the allocation under PPS, but this requires a temporary drop in inflation and a more pronounced initial output contraction. ${ }^{17}$

Interestingly, since optimal policy prevents an increase in entrepreneurs' net worth, leverage (not shown) is higher than under PPS despite lower investment. ${ }^{18}$ This reflects the fact that banks are perfectly safe in the model (risk is perfectly diversified), and thus there is no concern about the extent of leverage in the economy. Optimal policy limits the amplitude of investment fluctuations that arise out of the financial accelerator's externality by leaning against asset prices.

\footnotetext{
${ }^{16}$ The analysis is almost isomorphic for shocks to net worth (or $\gamma$-shocks) that are central to the analysis in Gilchrist and Leahy (2002). However, as explained in CMR (2010), these shocks have counterfactual implications for credit growth and are therefore less likely to be primary drivers of the business cycle. A description of the effects of shocks to net worth on the economy can be found in Leduc and Natal (2011).

${ }^{17}$ In Leduc and Natal (2011), we also considered a shock to net worth, as in Gilchrist and Leahy (2002). As for a negative $\sigma_{\omega}$-shock, the shock to net worth boosts asset prices, investment, and output. We showed that, in this case as well, optimal policy tends to dampen movements in asset prices, net worth, and finance premia compared to PPS.

${ }^{18}$ Under our calibration, optimal policy actually engineers a decrease in net worth.
} 


\subsection{The role of the financial friction and asset prices}

How important are movements in asset prices in determining the optimal monetary response? To isolate the effect of fluctuations in asset prices via the financial accelerator, we trim down the investment adjustment cost in equation (13). Mechanically, when changing investment is not costly, asset prices (Tobin's Q) do not need to increase by much to induce the required level of investment; in our example, asset prices remain almost fixed. Figure 4 shows the response of the economy to a positive productivity shock $\left(a_{t}\right)$ and to a drop in risk $\left(\sigma_{\omega, t}\right)$. It shows these responses under the optimal policy and price stability in the presence of investment adjustment costs (our benchmark case) and also under the optimal policy when investment can be freely adjusted, so that the asset price transmission channel is shut off. The figure shows that endogenous fluctuations in asset prices and their impact on net worth are first order in determining the optimal monetary response to shocks. When asset prices do not move, the optimal policy response to a productivity shock, for instance, is virtually identical to a policy targeting price stability, as the wedge between natural and efficient output remains almost constant, an issue we discuss in more detail below. The optimal policy response to the financial shock becomes also closer to price stability absent fluctuations in asset prices.

What is the importance of the model's financial friction in driving this result? Figure 5 contrasts the output and inflation responses under the optimal policy for different degrees of the financial friction. When financial frictions are nearly shut off (setting the monitoring cost $\mu=0.05)$, PPS is close to optimal following a productivity shock, as movement in asset prices are muted due to the weak financial accelerator. Similarly, following a financial shock the movements in output and inflation are somewhat muted when the size of the financial friction is reduced. ${ }^{19}$ This result again highlights the importance of the multiplier effects of asset prices on investment, i.e., the feedback loop through which an increase in asset prices boosts investment via a rise in net worth and a corresponding drop in the external finance premium. This dynamic effect pushes the economy to deviate substantially from the efficient

\footnotetext{
${ }^{19}$ In terms of financial shocks, Figure 4 and 5 only report the responses to a $\sigma_{\omega}$ shock, but the responses to a $\gamma$ shock would tell a similar story.
} 
allocation, and price stability is not the welfare-maximizing solution.

\subsection{The role of the subsidized steady state}

Most authors routinely assume that the government is able to levy a lump-sum tax and transfer the proceeds to workers in the form of an employment subsidy that compensates them for the welfare loss associated with the steady-state monopolistic competition distortion. This assumption makes the equilibrium under flexible prices efficient and, under certain conditions (see Woodford 2003), optimal monetary policy delivers the flexible price allocation (or constant markups and prices), which features PPS. Although this assumption is innocuous in a canonical New Keynesian model where the only other distortion is price stickiness (since the wedge between efficient and natural output is constant), it can have important consequences when the economy is simultaneously subject to another real friction, like the countercyclical credit market imperfections inherent to the financial accelerator model.

In general, the flexible price allocation does not maximize household welfare when there is a nontrivial real friction and when the steady-state markup is non-zero. ${ }^{20}$ As shown in Galí, Gertler, and Lopez-Salido (2007), the welfare loss from output fluctuations is increasing in the amount of steady-state distortion. In the case of a subsidized steady state, the welfare loss associated with inefficient output variations is dwarfed by the welfare cost of inflation, and price stability may remain the welfare-maximizing policy. Figure 6 shows that, indeed, the optimal policy responses to a productivity shock and to a drop in $\sigma_{\omega}$ are extremely close to PPS when a subsidy is available to offset the steady-state monopolistic competition distortion, even in the presence of financial frictions $(\mu=0.2)$. This result corroborates similar analysis by Carlstrom, Fuerst, and Paustian (2009) and Faia and Monacelli (2007).

In the financial accelerator model, a positive steady-state markup distortion is important because it results in a nonconstant wedge between the natural and optimal output response to shocks. As a result, welfare can be improved by deviating from price stability: trading

\footnotetext{
${ }^{20}$ See Adao, Correia, and Teles (2003) for a formal analysis in the context of a monetary model with cashin-advance constraints and firms that set prices one period in advance. Natal (2012) show that the flexible price allocation is not optimal either in models where oil enters as an imperfect substitute for other production factors and consumption goods.
} 
off some output variability against movements in inflation. Figure 7 shows that the larger the steady-state markup distortion, the larger is the variability of the wedge, and the larger the monetary policy trade-off. When the monopolistic distortion is subsidized away, there is essentially no trade-off, even if the steady state remains inefficient due to the presence of agency costs. Implicitly, agency costs induce suboptimal output fluctuations that are outweighed by the costs of inflation fluctuations. ${ }^{21}$

\subsection{Implementing optimal policy}

One problem with welfare-based optimal policies is their reliance on unobservables such as the efficient level of output or various shadow prices, which, in practice, makes them difficult to implement. A straightforward alternative is to rely on simple but suboptimal rules that are functions of observables only. Previous literature (see Walsh, 2003) has shown that the optimal precommitment monetary policy rule can be approximated by a simple inertial policy rule - or speed-limit rule - in the New Keynesian context. In particular, just as optimal policies with commitment, a speed-limit rule introduces inertia in output and inflation that would otherwise be absent with other level-based simple rules. To take into account the extra friction due to the financial accelerator, we append a financial variable to the rule and postulate the following general specification:

$$
\widehat{r_{t}}=g_{\pi} \widehat{\pi_{y, t}}+g_{\Delta y}\left(\widehat{y_{t}}-\widehat{y_{t-1}}\right)+g_{\Delta f}\left(\widehat{f i_{t}}-\widehat{f i_{t-1}}\right)
$$

where variables with a hat denote deviations from the steady state and $\widehat{f i_{t}}$ is our financial indicator. We consider a rule in which we set this indicator to equal the external finance premium. However, our results are robust to alternative measures such as equity prices, net worth, or loans because they are all interrelated via the optimal debt contract between banks and entrepreneurs. The general rule relies on a reasonable information set as only the growth rates of the variables are required. Using equation (14), we search for the simple rule (over the space of parameters $g_{\pi}, g_{\Delta y}$, and $\left.g_{\Delta f}\right)$ that best approximates the optimal precommitment

\footnotetext{
${ }^{21}$ Note that this result holds even for larger than one-standard-deviation shocks.
} 
plan. To do so, we simply maximize the economy's social welfare function using a second-order approximation to the economy's equilibrium conditions and welfare function. ${ }^{22}$

Figures 8 and 9 show impulse responses to a productivity shock, $a_{t}$, and a risk shock, $\sigma_{\omega}$, under the optimal plan, the optimized speed-limit rule, and a traditional Taylor rule. The first part of Table 2 reports the value of the parameters of the optimized rule for the different exercises using our benchmark model ignoring macroprudential policy. ${ }^{23}$ The optimized rule leans strongly against inflation (because of the price friction) and the change in risk premium (because of the financial friction), but does not react to the change in output $\left(g_{\Delta y}=0\right)$. Moreover, the financial friction is quantitatively important and leads the monetary authority to place a very large weight on the growth in the equity finance premium. Figures 8 and 9 show that our speed-limit rule reproduces very closely the allocation generated under the optimal policy and particularly leads to inertial, hump-shaped movements in many variables. In contrast, the standard Taylor rule often misses on the magnitude, and sometimes on the sign, of the variables' responses under the optimal policy and typically doesn't generate hump-shaped movements.

The importance of leaning against changes in financial variables is highlighted in Figure 10, which compares the responses to each shock when the weight on the growth of the financial indicator in the speed-limit rule is reduced compared to that in the optimized rule. The figure shows that a larger weight on the change in $f i_{t}$ helps create more inertial responses, particularly for investment and output. When the policymaker leans less against changes in the risk premium, investment responds too much too quickly, which leads to suboptimal movements in consumption (not shown) and output. Strikingly, even relatively modest responses to changes in $f i_{t}$ produce results that are pretty close to the optimized policy.

As a final exercise, we also searched for the parameters of the speed-limit rule that best match the optimal plan when the two shocks are considered simultaneously. The result, shown

\footnotetext{
${ }^{22}$ See also Benigno and Woodford (2005) and Dennis (1999) for discussions of the importance of taking a second-order approximation to the model solution and issues with the linear-quadratic approach.

${ }^{23}$ Note also that similar results would be obtained with rules that lean against other financial variables such as equity prices, net worth, or loans because they are all interrelated via the optimal debt contract between banks and entrepreneurs.
} 
in the last row of Table 2, is qualitatively similar to the individual shock exercises presented in Figures 8 and 9 .

Overall, we take from this exercise that, absent macroprudential policy, a speed-limit rule with a substantial weight on inflation and on the change in the risk premium does a good job at mimicking the optimal plan. While the optimized weight on the financial variable is rather large, we take this particular value literally. Indeed, Figure 10 shows that even a significantly smaller weight on the change in the risk premium goes a long way in approximating the optimal monetary policy.

\subsection{Macroprudential Policy}

In this section, we introduce macroprudential policy and study how it impacts the optimal monetary policy in the benchmark model. In particular, we examine a simple, implementable, rule that positively links reserve requirements to changes in credit growth. We focus on credit growth since the literature has emphasized this variable as a useful indicator of financial imbalances (see, for instance, Basel III).

We consider two cases:. First, when the sensitivity of reserve requirements to credit growth is optimized $(\chi=1.0064)$; second, when macroprudential policy responds more forcefully to credit growth $(\chi=3)$. Figures 11 and 12 show the responses of the economy to a productivity and a risk shock under these two macroprudential rules, when monetary policy is set optimally. Each figure also reports the responses under our benchmark economy without reserve requirements.

The figures show that introducing a simple reserve requirement rule substantially dampens the need for the optimal monetary policy to raise interest rates in the face of expansionary shocks. Following a productivity shock (Figure 11), for instance, reserve requirements increase in line with credit growth, pushing up the premium over the return on the risk-free asset. Since part of the banks' source of funds must be held in reserves earning zero return, extending credit becomes more costly, which is reflected in a higher interest rate spread. In turn, the increase in reserve requirements curbs the rise in equity prices and investment in the short run. Interest- 
ingly, the interest rate needs to rise less in the presence of macroprudential policy, since reserve requirement partly mutes the effect of the financial accelerator. In contrast to the benchmark economy, if reserve requirements respond more aggressively to credit growth $(\psi=3)$, the optimal monetary policy reaction to productivity shocks is to lower the real interest rate. In this case, inflation is also nearly stabilized, but the increase in investment is too muted. ${ }^{24}$ These results highlight the extent of substitutability between monetary and macroprudential policies. A tighter (looser) macroprudential policy allows a looser (tighter) monetary response.

Similar effects can be observed following a risk shock, as shown in Figure 12. Again, the presence of a simple reserve requirement rule allows for a smaller rise in the interest rate and a substantially more muted response of the economy overall.

As in the previous section, we can approximate the optimal monetary policy by an interest rate rule, given a particular policy for reserve requirements. As anticipated by the results in Figures 11 and 12, the last three columns of Table 2 show that the optimal monetary policy leans dramatically less against movements in financial variables when the macroprudential rule is optimized $(\chi=1.0064)$. In this case, the weight on the financial indicator in the speed-limit rule is 0 in response to productivity and financial shocks.

Finally, we conduct a welfare analysis of the different policy combinations in Table 3, with the details of our welfare calculation described in Appendix IV. The table reports the welfare loss-measured in percent of yearly steady-state consumption-associated with alternative monetary policies under different assumptions regarding the sensitivity of the reserve requirements to credit growth. The table first shows that under our benchmark economy the welfare cost of pursuing price stability is substantial, reaching roughly 1.3 percent of yearly consumption. Adopting a Taylor rule brings about an even higher cost.

However, the welfare costs of alternative monetary policy rules are dramatically reduced in the presence of macroprudential policy. In particular, the welfare costs of pursuing price stability becomes negligible, as the negative effects of financial shocks on welfare are mitigated with reserve requirements that respond to credit growth. So, while Stein's (2013) argument that

\footnotetext{
${ }^{24}$ For instance, investment rises much less than the efficient response in this case (not shown).
} 
monetary policy should deviate from price stability and respond to financial imbalances is captured by our benchmark economy in which macroprudential policy is unavailable to policymakers, quasi price stability reemerges in the presence of a simple, implementable, macroprudential rule that solely reacts to credit growth.

\section{Conclusion}

The financial crisis has forced policymakers and academics to revisit the role of financial variables in the conduct of monetary policy. Our work is in this vein and shows that, in the seminal framework of Bernanke, Gertler, and Gilchrist (1999), optimal policy trades off short-run inflation stabilization for a more efficient allocation of production by leaning against movements in asset prices particularly in response to financial shocks. Our result hinges on the presence of two reasonable conditions. First, the natural allocation must differ from the efficient one, with a wedge between the two that varies along the business cycle. This naturally occurs in the model when we realistically abstract from the presence of employment subsidies to monopolistic firms. Second, the economy must be subject to an endogenous feedback loop between asset prices and economic fluctuations. Absent that feedback, a policy of strict inflation targeting remains the optimal prescription for monetary policy. We also show that in practice the optimal monetary policy can be well approximated by a speed-limit interest rate rule that places a large weight on deviations of inflation from a target and on the growth rate of financial variables. Thanks to the presence of a large feedback coefficient on inflation, monetary policy does not allow inflation expectations to become unanchored as a result of the trade-off.

Our benchmark model abstracts from macroprudential policy and thus broadly captures Stein's (2013) argument that, because macroprudential policy may be unavailable or difficult to adjust on a timely basis, monetary policy may have a role to play to contain financial "excesses." However, we show that even a simple macroprudential rule that positively links reserve requirements to credit growth substantially dampens the endogenous feedback loop and allows optimal monetary policy to focus exclusively on price stability.

Our analysis abstracted from the presence of financial constraints on banks and other 
financial institutions, which clearly played an important role during the financial crisis. We conjecture that qualitatively our results would also hold in a model with those features (see Gertler and Karad (2009), Gertler and Kiyotaki (2010), or Brunnermeier and Sannikov (2011) for models with constraints on financial institutions). However, the extent to which the optimal monetary policy leans against changes in financial variables and the role of macroprudential policy may very well depend on whether or not financial institutions also face financial constraints. We intend to pursue this avenue in future research. 


\section{Appendix I: The contract (not for publication)}

The contract specifies a level of loans, $B_{j, t+1}$ and a gross interest rate $R_{j, t+1}^{b}$ that maximizes the expected profit of the entrepreneur subject to the participation constraint of the financial intermediary (the bank), or identically a level of capital and a cutoff point.

To simplify matters, it is convenient to operate certain substitutions. ${ }^{25}$ Let us first introduce:

$$
\Gamma(\omega)=\omega(1-F(\omega))+G(\omega) \text { and } G(\omega)=\int_{0}^{\omega} x \mathrm{~d} F(x)
$$

which satisfy

$$
\begin{aligned}
& \Gamma^{\prime}(\omega)=1-F(\omega) \\
& G^{\prime}(\omega)=\omega F^{\prime}(\omega) .
\end{aligned}
$$

The expected profit of the entrepreneur is given by equation (6), which rewrites as

$$
E_{t}\left[\int_{\omega_{j, t+1}^{\star}}^{\infty} \omega \mathrm{d} F(\omega) R_{t+1}^{k}-\omega_{j, t+1}^{\star} \int_{\omega_{j, t+1}^{\star}}^{\infty} \mathrm{d} F(\omega) R_{t+1}^{k}\right] Q_{t} k_{j, t+1} .
$$

Note that since $E(\omega)=1$, we have

$$
1=\int_{0}^{\infty} \omega \mathrm{d} F(\omega)=\int_{0}^{\omega_{j, t+1}^{\star}} \omega \mathrm{d} F(\omega)+\int_{\omega_{j, t+1}^{\star}}^{\infty} \omega \mathrm{d} F(\omega)
$$

such that

$$
\int_{\omega_{j, t+1}^{\star}}^{\infty} \omega \mathrm{d} F(\omega)=1-\int_{0}^{\omega_{j, t+1}^{\star}} \omega \mathrm{d} F(\omega)=1-G\left(\omega_{j, t+1}^{\star}\right) .
$$

Hence, the expected profit function rewrites

$$
E_{t}\left[\left[1-G\left(\omega_{j, t+1}^{\star}\right)-\omega_{j, t+1}^{\star}\left(1-F\left(\omega_{j, t+1}^{\star}\right)\right)\right] R_{t+1}^{k}\right] Q_{t} k_{j, t+1}
$$

which can be compactly written as

$$
E_{t}\left[\left[1-\Gamma\left(\omega_{j, t+1}^{\star}\right)\right] R_{t+1}^{k}\right] Q_{t} k_{j, t+1}
$$

\footnotetext{
${ }^{25}$ Note that we consider the steady-state contract only. As $\sigma_{\omega, t}$ takes the form of a "risk shock" in certain simulations presented, the equations must be updated accordingly.
} 
Given the reserve requirement, $\phi_{t}$, determining the fraction of loanable deposits, the financial intermediary issues $B_{j, t+1} /\left(1-\phi_{t}\right)$ deposits to finance $B_{j, t+1}$ loans per entrepreneurs. Therefore, combining the participation constraint (8) with the definition of the cutoff we can write:

$$
\left[\left(1-F\left(\omega_{j, t+1}^{\star}\right)\right) \omega_{j, t+1}^{\star}+(1-\mu) \int_{0}^{\omega_{j, t+1}^{\star}} \omega \mathrm{d} F(\omega)\right] Q_{t} R_{t+1}^{k} k_{j, t+1}=R_{t} \frac{B_{j, t+1}}{\left(1-\phi_{t}\right)}
$$

or identically

$$
\left[\left(\Gamma\left(\omega_{j, t+1}^{\star}\right)\right)-\mu G\left(\omega_{j, t+1}^{\star}\right)\right] Q_{t} R_{t+1}^{k} k_{j, t+1}=R_{t} \frac{B_{j, t+1}}{\left(1-\phi_{t}\right)} .
$$

Then using the fact that $Q_{t} k_{j, t+1}=N_{j, t+1}+B_{j, t+1}$ we rewrite the equation above as

$$
\left[\left(\Gamma\left(\omega_{j, t+1}^{\star}\right)\right)-\mu G\left(\omega_{j, t+1}^{\star}\right)\right] Q_{t} R_{t+1}^{k} k_{j, t+1}=R_{t} \frac{\left(Q_{t} k_{j, t+1}-N_{j, t+1}\right)}{\left(1-\phi_{t}\right)} .
$$

The CSV problem therefore amounts to finding a cutoff point $\omega_{j, t+1}^{\star}$ and a level of capital $k_{j, t+1}$ that solves

$$
\begin{aligned}
& \max _{\left\{\omega_{j, t+1}^{\star}, k_{j, t+1}\right\}} E_{t}\left[\left[1-\Gamma\left(\omega_{j, t+1}^{\star}\right)\right] R_{t+1}^{k}\right] Q_{t} k_{j, t+1} \\
& {\left[\left(\Gamma\left(\omega_{j, t+1}^{\star}\right)\right)-\mu G\left(\omega_{j, t+1}^{\star}\right)\right] Q_{t} R_{t+1}^{k} k_{j, t+1}=R_{t} \frac{\left(Q_{t} k_{j, t+1}-N_{j, t+1}\right)}{\left(1-\phi_{t}\right)} .}
\end{aligned}
$$

Denoting by $\Psi_{t+1}$ the Lagrange multiplier associated with the constraint, and remembering that $\omega_{j, t+1}^{\star}$ is indexed by each possible $R_{t+1}^{k}$, the set of first-order conditions is given by

$$
\begin{aligned}
E_{t}\left[\left[1-\Gamma\left(\omega_{j, t+1}^{\star}\right)\right] R_{t+1}^{k}+\Psi_{t+1}\left(\left[\left(\Gamma\left(\omega_{j, t+1}^{\star}\right)\right)-\mu G\left(\omega_{j, t+1}^{\star}\right)\right] R_{t+1}^{k}-\frac{R_{t}}{\left(1-\phi_{t}\right)}\right)\right] & =0 \\
-\Gamma^{\prime}\left(\omega_{j, t+1}^{\star}\right)+\Psi_{t+1}\left(\Gamma^{\prime}\left(\omega_{j, t+1}^{\star}\right)-\mu G^{\prime}\left(\omega_{j, t+1}^{\star}\right)\right) & =0 \\
\Psi_{t+1}\left[\left(\left[\left(\Gamma\left(\omega_{j, t+1}^{\star}\right)\right)-\mu G\left(\omega_{j, t+1}^{\star}\right)\right] Q_{t} R_{t+1}^{k} k_{j, t+1}-R_{t}\left(\frac{Q_{t} k_{j, t+1}-N_{j, t+1}}{\left(1-\phi_{t}\right)}\right)\right]\right. & =0
\end{aligned}
$$

Restricting ourselves to interior solutions, we have $\Psi_{t+1}>0$ and the system becomes

$$
\begin{aligned}
E_{t}\left[\left[1-\Gamma\left(\omega_{j, t+1}^{\star}\right)\right] R_{t+1}^{k}+\frac{\Gamma^{\prime}\left(\omega_{j, t+1}^{\star}\right)}{\Gamma^{\prime}\left(\omega_{j, t+1}^{\star}\right)-\mu G^{\prime}\left(\omega_{j, t+1}^{\star}\right)}\left(\left[\Gamma\left(\omega_{j, t+1}^{\star}\right)-\mu G\left(\omega_{j, t+1}^{\star}\right)\right] R_{t+1}^{k}-\frac{R_{t}}{\left(1-\phi_{t}\right)}\right)\right] & =0 \\
{\left[\left(\Gamma\left(\omega_{j, t+1}^{\star}\right)\right)-\mu G\left(\omega_{j, t+1}^{\star}\right)\right] Q_{t} R_{t+1}^{k} k_{j, t+1}-R_{t} \frac{\left(Q_{t} k_{j, t+1}-N_{j, t+1}\right)}{\left(1-\phi_{t}\right)} } & =0
\end{aligned}
$$


Recalling that $\Gamma^{\prime}\left(\omega_{j, t+1}^{\star}\right)=1-F\left(\omega_{j, t+1}^{\star}\right), G^{\prime}\left(\omega_{j, t+1}^{\star}\right)=\omega_{j, t+1}^{\star} \Gamma^{\prime}\left(\omega_{j, t+1}^{\star}\right)$, and defining $h\left(\omega_{j, t+1}^{\star}\right)=$ $\Gamma^{\prime}\left(\omega_{j, t+1}^{\star}\right) /\left(1-F\left(\omega_{j, t+1}^{\star}\right)\right)$, we can reduce the system to

$$
\begin{aligned}
E_{t}\left[\left[1-\Gamma\left(\omega_{j, t+1}^{\star}\right)\right] R_{t+1}^{k}+\frac{\left[\Gamma\left(\omega_{j, t+1}^{\star}\right)-\mu G\left(\omega_{j, t+1}^{\star}\right)\right] R_{t+1}^{k}-\frac{R_{t}}{\left(1-\phi_{t}\right)}}{1-\mu \omega_{j, t+1}^{\star} h\left(\omega_{j, t+1}^{\star}\right)}\right] & =0 \\
{\left[\Gamma\left(\omega_{j, t+1}^{\star}\right)-\mu G\left(\omega_{j, t+1}^{\star}\right)\right] Q_{t} R_{t+1}^{k} k_{j, t+1}-R_{t} \frac{\left(Q_{t} k_{j, t+1}-N_{j, t+1}\right)}{\left(1-\phi_{t}\right)} } & =0 .
\end{aligned}
$$

It is clear from the first equation that $\omega_{j, t+1}^{\star}$ only depends on $R_{t+1}^{k}, R_{t}$, and $\phi_{t}$. Therefore, we have $\omega_{j, t+1}^{\star}=\omega_{t+1}^{\star}$ for all $j$, such that

$$
\begin{aligned}
E_{t}\left[\left[1-\Gamma\left(\omega_{t+1}^{\star}\right)\right] R_{t+1}^{k}+\frac{\left.\left[\Gamma\left(\omega_{t+1}^{\star}\right)-\mu G\left(\omega_{t+1}^{\star}\right)\right] R_{t+1}^{k}-\frac{R_{t}}{\left(1-\phi_{t}\right)}\right]}{1-\mu \omega_{t+1}^{\star} h\left(\omega_{t+1}^{\star}\right)}=0\right. \\
{\left[\Gamma\left(\omega_{t+1}^{\star}\right)-\mu G\left(\omega_{t+1}^{\star}\right)\right] Q_{t} R_{t+1}^{k} k_{j, t+1}-R_{t} \frac{\left(Q_{t} k_{j, t+1}-N_{j, t+1}\right)}{\left(1-\phi_{t}\right)}=0 . }
\end{aligned}
$$

\section{Appendix II: Aggregation and Equilibrium(not for publication)}

This section discusses the evolution of aggregate net worth, denoted by $N_{t+1}$. At this stage it is useful to introduce the distribution of net worth, $\Upsilon(N)$, such that

$$
N_{t+1}=\int_{0}^{\infty} N d \Upsilon(N) .
$$

Recalling that the capital stock held by an individual $j$ is a function of individual net worth, it is clear that aggregate capital $k_{t+1}$ is given by

$$
k_{t+1}=\int_{0}^{\infty} k_{t+1}(N) d \Upsilon(N)
$$

Noting that equation (16) is linear in both $k_{j, t+1}$ and $N_{j, t+1}$, we have, aggregating over individuals

$$
\begin{aligned}
E_{t}\left[\left[1-\Gamma\left(\omega_{t+1}^{\star}\right)\right] R_{t+1}^{k}+\frac{\left[\Gamma\left(\omega_{t+1}^{\star}\right)-\mu G\left(\omega_{t+1}^{\star}\right)\right] R_{t+1}^{k}-\frac{R_{t}}{\left(1-\phi_{t}\right)}}{1-\mu \omega_{t+1}^{\star} h\left(\omega_{t+1}^{\star}\right)}\right] & =0 \\
{\left[\Gamma\left(\omega_{t+1}^{\star}\right)-\mu G\left(\omega_{t+1}^{\star}\right)\right] Q_{t} R_{t+1}^{k} k_{t+1}-R_{t} \frac{\left(Q_{t} k_{t+1}-N_{t+1}\right)}{\left(1-\phi_{t}\right)} } & =0 .
\end{aligned}
$$


In equilibrium, the fraction of loanable deposits held at financial intermediaries must equal the total funds supplied to entrepreneurs. The fraction of loanable deposits depends on the particular macroprudential policy pursued. Thus, we have $B_{t+1}=Q_{t} k_{t+1}-N_{t+1}=\phi_{t} D_{t}$.

We now turn our attention to the law of motion of aggregate net worth. Let us denote by $\Xi_{j, t}$ the average actual profit of an individual entrepreneur in period $t$,

$$
\Xi_{j, t}=\left[1-\Gamma\left(\omega_{t}^{\star}\right)\right] R_{t}^{k} Q_{t-1} k_{j, t} .
$$

Note that this individual profit is linear in $k_{j, t}$, such that aggregate profit flow is given by

$$
\int_{0}^{\infty} \Xi_{t}(N) d \Upsilon(N)=\left[1-\Gamma\left(\omega_{t}^{\star}\right)\right] R_{t}^{k} Q_{t-1} \int_{0}^{\infty} k_{t}(N) d \Upsilon(N)
$$

and

$$
\Xi_{t}=\left[1-\Gamma\left(\omega_{t}^{\star}\right)\right] R_{t}^{k} Q_{t-1} k_{t} .
$$

Since entrepreneurs are randomly drawn for survival with probability $\gamma_{t}$, and newly born entrepreneurs receive a transfer $\tau_{t}^{e}$ from the government, aggregate net worth evolves as

$$
N_{t+1}=\gamma_{t} \Xi_{t}+\tau_{t}^{e}
$$

or

$$
N_{t+1}=\gamma_{t}\left[1-\Gamma\left(\omega_{t}^{\star}\right)\right] R_{t}^{k} Q_{t-1} k_{t}+\tau_{t}^{e} .
$$

The $\left(1-\gamma_{t}\right)$ entrepreneurs selected to close their business consume a constant share $\chi$ of their profit, the remaining being kept by the government to finance transfers to newly born entrepreneurs. Hence

$$
P_{t} c_{t}^{e}=\left(1-\gamma_{t}\right) \chi\left[1-\Gamma\left(\omega_{t}^{\star}\right)\right] R_{t}^{k} Q_{t-1} k_{t} .
$$




\section{Appendix III: Risk (not for publication)}

In this Appendix we come back to the determination of $\omega^{\star}$. Recall that we use a log-normal distribution for $\omega$, such that

$$
F\left(\omega^{\star}\right)=\frac{1}{\sigma_{\omega} \sqrt{2 \pi}} \int_{0}^{\log \left(\omega^{\star}\right)} e^{-\frac{1}{2}\left(\frac{x-\mu_{\omega}}{\sigma_{\omega}}\right)^{2}} \mathrm{~d} x .
$$

Making the change of variable $y=\frac{x-\mu_{\omega}}{\sigma_{\omega}}$, we have

$$
F\left(\omega^{\star}\right)=\frac{1}{\sqrt{2 \pi}} \int_{0}^{\frac{\log \left(\omega^{\star}\right)-\mu_{\omega}}{\sigma_{\omega}}} e^{-\frac{y}{2}} \mathrm{~d} y=\Phi\left(\frac{\log \left(\omega^{\star}\right)-\mu_{\omega}}{\sigma_{\omega}}\right)
$$

where $\Phi(\cdot)$ denotes the cdf of the normal distribution.

Likewise,

$$
G\left(\omega^{\star}\right)=\frac{1}{\sigma_{\omega} \sqrt{2 \pi}} \int_{0}^{\log \left(\omega^{\star}\right)} e^{x} e^{-\frac{1}{2}\left(\frac{x-\mu_{\omega}}{\sigma_{\omega}}\right)^{2}} \mathrm{~d} x .
$$

Making a first change of variable $y=\frac{x-\mu_{\omega}}{\sigma_{\omega}}$, we have

$$
G\left(\omega^{\star}\right)=\frac{e^{\mu_{\omega}}}{\sqrt{2 \pi}} \int_{0}^{\frac{\log \left(\omega^{\star}\right)-\mu_{\omega}}{\sigma_{\omega}}} e^{-\frac{1}{2}\left(y^{2}-2 \sigma_{\omega} y\right)} \mathrm{d} y .
$$

Adding and substracting $\sigma_{\omega} / 2$ in the exponential under the integral, we have

$$
G\left(\omega^{\star}\right)=\frac{e^{\mu_{\omega}+\frac{\sigma_{\omega}^{2}}{2}}}{\sqrt{2 \pi}} \int_{0}^{\frac{\log \left(\omega^{\star}\right)-\mu_{\omega}}{\sigma_{\omega}}} e^{-\frac{1}{2}\left(y-\sigma_{\omega}\right)^{2}} \mathrm{~d} y .
$$

Making a last change of variable $z=y-\sigma_{\omega}$, this rewrites as

$$
G\left(\omega^{\star}\right)=\frac{e^{\mu_{\omega}+\frac{\sigma_{\omega}^{2}}{2}}}{\sqrt{2 \pi}} \int_{0}^{\frac{\log \left(\omega^{\star}\right)-\mu_{\omega}}{\sigma_{\omega}}-\sigma_{\omega}} e^{-\frac{z^{2}}{2}} \mathrm{~d} z=e^{\mu_{\omega}+\frac{\sigma_{\omega}^{2}}{2}} \Phi\left(\frac{\log \left(\omega^{\star}\right)-\mu_{\omega}}{\sigma_{\omega}}-\sigma_{\omega}\right) .
$$

Since $E(\omega)=1, G\left(\omega^{\star}\right)$ reduces to

$$
G\left(\omega^{\star}\right)=\Phi\left(\frac{\log \left(\omega^{\star}\right)-\mu_{\omega}}{\sigma_{\omega}}-\sigma_{\omega}\right)
$$

Note finally that $E(\omega)=1$ imposes $\mu_{\omega}=-\frac{\sigma_{\omega}^{2}}{2}$. Therefore, in the case of a risk shock, $\mu_{\omega, t}=$ $-\frac{\sigma_{\omega, t}^{2}}{2}$. 


\section{Appendix IV. Welfare Cost of Alternative Monetary Policies (not for publication)}

To find the welfare cost of following suboptimal monetary policies, we follow Schmitt-Grohe and Uribe (2007). We compute the percent loss of steady-state consumption that the household suffers as follows.

Let $W^{A}$ be the household welfare under the suboptimal (alternative) policies and let $W^{F B}$ be the household welfare under the optimal policy. We compute the welfare cost, $\lambda$, of being in an economy with the suboptimal policy by finding the drop in consumption, under the optimal policy, that would equalize welfare under the two policies.

$$
\begin{aligned}
& W_{t}^{A}=W_{t}^{F B}=E_{0} \sum_{t=0}^{\infty} \beta^{t}\left[\frac{\left(C_{t}^{F B}(1-\lambda)\right)^{1-\sigma_{c}}}{1-\sigma_{c}}-\nu_{h} \frac{L_{t}^{F B} 1+\sigma_{h}}{1+\sigma_{h}}\right] \\
& W_{t}^{A}-\left[-E_{0} \sum_{t=0}^{\infty} \beta^{t} \nu_{h} \frac{\left(L_{t}^{F B}\right)^{1+\sigma_{h}}}{1+\sigma_{h}}\right]=(1-\lambda)^{1-\sigma_{c}}\left[E_{0} \sum_{t=0}^{\infty} \beta^{t} \frac{\left(C_{t}^{F B}\right)^{1-\sigma_{c}}}{1-\sigma_{c}}\right]
\end{aligned}
$$

Define:

$$
W_{L, t}^{F B}=-E_{0} \sum_{t=0}^{\infty} \beta^{t} \nu_{h} \frac{\left(L_{t}^{F B}\right)^{1+\sigma_{h}}}{1+\sigma_{h}}
$$

and

$$
W_{C, t}^{F B}=E_{0} \sum_{t=0}^{\infty} \beta^{t} \frac{\left(C_{t}^{F B}\right)^{1-\sigma_{c}}}{1-\sigma_{c}}
$$

Then

$$
\begin{aligned}
& W_{t}^{A}-W_{L, t}^{F B}=(1-\lambda)^{1-\sigma_{c}} W_{C, t}^{F B} \\
& \lambda=1-\left[\frac{W_{t}^{A}-W_{L, t}^{F B}}{W_{C, t}^{F B}}\right]^{\frac{1}{1-\sigma_{c}}} .
\end{aligned}
$$

We compute the welfare cost using a second-order approximation using the algorithm of Coenen et al. (2010). To do so we write the infinite sums above recursively. 


\section{References}

[1] Adāo, Bernardino, Isabel Correia, and Pedro Teles, (2003), "Gaps and Triangles," Review of Economic Studies 70, pp. 699-713.

[2] Angelini, Paolo, Stefano Neri and Fabio Panetta, (2014), "The Interaction Between Capital Requirements and Monetary Policy," Journal of Money, Credit, and Banking 46(6), pp. 1073-1112.

[3] Angeloni, Ignazio and Ester Faia, (2013), "Capital Regulation and Monetary Policy with Fragile Banks," Journal of Monetary Economics 60, pp. 311-324.

[4] Beau, Denis, Clerc, Laurent, and Benoit Mojon, (2011), "Macro-Prudential Policy and the Conduct of Monetary Policy," Banque de France Working Papers.

[5] Benigno, Pierpaolo and Michael Woodford (2005), "Inflation Stabilization and Welfare: The Case of a Distorted Steady State," Journal of the European Economic Association 3, pp. 1185-1236.

[6] Bernanke, Ben, and Mark Gertler (1999), "Monetary Policy and Asset Volatility," Federal Reserve Bank of Kansas City Economic Review, Fourth Quarter 1999, 84(4), pp. 17-52.

[7] Bernanke, Ben and Mark Gertler (2001), "Should Central Banks Respond to Movements in Asset Prices," American Economic Review Papers and Proceedings 91, 253-257.

[8] Bernanke, Ben, Mark Gertler, and Simon Gilchrist (1999), The Financial Accelerator in a Quantitative Business Cycle Framework," in John B. Taylor and Michael Woodford, eds., Handbook of Macroeconomics, vol. 1C, Amsterdam: North-Holland.

[9] Brunnermeier, Markus K. and Yuliy Sannikov (2011), "A Macroeconomic Model with a Financial Sector," manuscript.

[10] Carlstrom, Charles C. and Timothy S. Fuerst (1997), "Agency Costs, Net Worth, and Business Fluctuations: A Computable General Equilibrium Analysis," American Economic Review 87, pp.893-910. 
[11] Carlstom, Charles T. C., Timothy S. Fuerst, and Matthias Paustian (2010), "Optimal Monetary Policy In a Model with Agency Costs," Journal of Money Credit and Banking, 42(1), pp. 37-70.

[12] Collard, Fabrice, Dellas, Harris, Diba, Behzad, and Olivier Loisel (2013), "Optimal Monetary and Prudential Policies," manuscript.

Christensen, Ian, Césaire Meh, and Kevin Moran, (2011), "Bank Leverage and Macroeconomic Dynamics," Bank of Canada Working Paper 2011-32.

[13] Christiano, Lawrence J., Roberto Motto, and Massimo Rostagno, (2003), "The Great Depression and the Friedman-Schwartz Hypothesis," Journal of Money, Credit and Banking 35(6), pp. 1119-1198.

[14] Christiano, Lawrence J. and Daisuke Ikeda, (2011), "Government Policy, Credit markets and the Economy," NBER Working Paper 17142.

[15] Christiano, Lawrence J., Roberto Motto, and Massimo Rostagno, (2010), "Financial Factors in Economic Fluctuations," ECB Working Paper 1192.

[16] Christiano, Lawrence J., Roberto Motto, and Massimo Rostagno, (2014), "Risk Shocks," American Economic Review 104(1), pp. 27-65.

[17] Claessens, Stijn, Ghosh, Swati R., and Roxana Mihet, (2014), "Macro-Prudential Policies to Mitigate Financial System Vulnerabilities," IMF Working paper 14/155.

[18] Coenen, Günter, Lombardo, Giovanni, Smets, Frank and Roland Straub, (2010), "International Transmission and Monetary Policy Cooperation," in Jordi Galí and Mark Gertler (eds), International Dimensions of Monetary Policy, NBER, Cambridge, M.A., Chapter 3, 175-192.

[19] Collard, Fabrice, Dellas, Harris, Diba, Behzad, and Olivier Loisel, (2012), "Optimal Monetary Policy and Prudential Policies," Banque de France Document de Travail no. 413.

[20] Curdia, Vasco, and Michael Woodford, (2009) "Credit Frictions and Optimal Monetary Policy," BIS Working Paper \#278, Bank for International Settlements. 
[21] De Fiore, Fiorella, Pedro Teles and Oreste Tristani (2011), "Monetary Policy and the Financiing of Firms," American Economic Journals: Macroeconomics 3, pp. 1-31.

[22] De Fiore, Fiorella and Oreste Tristani (2013), "Optimal Monetary Policy in a Model of the Credit Channel," Economic Journal 123(571), pp. 906-931.

[23] Dennis, Richard (2004), "Solving for Optimal Simple Rules in Rational Expectations Models," Journal of Economic Dynamics and Control 28(8), pp. 1635-1660.

[24] Faia, Ester and Tommaso Monacelli (2007), "Optimal Interest-Rate Rules, Asset Prices, and Credit Frictions," Journal of Economic Dynamics and Control 31, pp. 3228-3254.

[25] Federico, Pablo, Vegh, Carlos A. and Guillermo Vuletin, (2012), "Reserve Requirement Policy Over the Business Cylce," manuscript.

[26] Galí, Jordi, Gertler Mark, and David Lopez-Salido (2007), "Markups, Gaps, and the Welfare Costs of Business Fluctuations," Review of Economics and Statistics 89(1), pp. 44-59.

[27] Gertler, Mark and Peter Karadi, (2009), "A Model of Unconventional Monetary Policy," manuscript.

[28] Gertler, Mark and Nobuhiro Kiyotaki (2010), "Financial Intermediation and Credit Policy in Business Cycle Analysis," in Benjamin M. Friedman and Michael Woodford, eds, Handbook of Monetary Economics, vol 3A, pp 547-600.

[29] Gilchrist, Simon and John V. Leahy (2002), "Monetary Policy and Asset Prices," Journal of Monetary Economics 49(1), pp. 75-97.

[30] Gilchrist, Simon and Masashi Saito (2008), "Expectations, Asset Prices, and Monetary Policy: The Role of Learning," in John Y. Campbell, ed. Asset Prices and Monetary Policy, Chicago: University of Chicago Press.

[31] Gilchrist, Simon and Egon Zakrajšek, (2012), "Credit Supply Shocks and Economic Activity in a Financial Accelerator Model," in Alan Blinder, Andrew Lo and Robert Solow (eds), Rethinking the Financial Crisis. 
[32] Kashyap, Anil and jeremy C. Stein, (2012), "The optimal Conduct of Monetary Policy with Interest on Reserves, American Economic Journal: Macroeconomics 4, pp. 266-282.

[33] Kiyotaki, Nobuhiro and John H. Moore, (1997), "Credit Cycles," Journal of Political Economy, 105(2), pp. 211-248.

[34] Leduc, Sylvain and Jean-Marc Natal, (2011), "Should Central Banks Lean Against Asset Prices," Federal Reserve Bank of San Francisco Working Paper 2011-15.

[35] Natal, Jean-Marc, (2012), "Monetary Response to Oil Price Shocks," Journal of Money, Credit, and Banking 44, pp. 53-101.

[36] Quint, Dominic and Pau Rabanal, (2013), "Monetary and Macroprudential Policy in an Estimated DSGE Model of the Euro Area," IMF Working Paper 13/2009.

[37] Schmitt-Grohe, Stephanie and Martin Uribe, (2007), "Optimal, Simple, and Implementable Monetary and Fiscal Rules," Journal of Monetary Economics 54, pp. 17021725.

[38] Stein, Jeremy C. (2013), "Overheating in Credit Markets: Origins, Measurement, and Policy Responses," speech delivered at "Restoring Household Financial Stability after the Great Recession: Why Household Balance Sheets Matter," a symposium sponsored by the Federal Reserve Bank of St. Louis.

[39] Stein, Jeremy C. (2014), "Incorporating Financial Stability Considerations Into a Monetary Policy Framework," speech delivered at the "International Research Forum on Monetary Policy" organized by the European Central Bank, the Federal Reserve Board, the Center for Financial Studies at the Goethe University, and the Georgetown Center for Economic Research at Georgetown University.

[40] Taylor, Alan M., and Moritz Schularick, (2012). "Credit Booms Gone Bust: Monetary Policy, Leverage Cycle, and Financial Crises 1870-2009," American Economic Review.102(2), pp. 1029-61.

[41] Tetlow, Robert J. (2006), "Monetary Policy, Asset Prices and Misspecification: The Robust 
Approach to Bubbles with Model Uncertainty," in Issues in Inflation Targeting (Ottawa: The Bank of Canada).

[42] Walsh, Carl E. (2003), "Speed Limit Policies: The Output Gap and Optimal Monetary Policy," American Economic Review 93(1), pp. 265-278.

[43] Woodford, Michael (2003). Interest and Prices: Foundations of a Theory of Monetary Policy, Princeton: Princeton University Press.

[44] Woodford, Michael (2012). "Inflation Targeting and Financial Stability, "Sveriges Riksbank Economic Review, pp. 7-32.

[45] Yellen, Janet L. (2009), "A Minsky Meltdown: Lessons for Central Bankers,"speech to the 18th Annual Hyman P. Minsky Conference on the State of the U.S. and World Economies - "Meeting the Challenges of the Financial Crisis" organized by the Levy Economics Institute of Bard College, New York, NY. 
Households and production

\begin{tabular}{|c|c|c|}
\hline Discount rate & $\beta$ & 0.990 \\
\hline Frisch elasticity & $\sigma_{h}$ & 1.000 \\
\hline Intertemporal elasticity of substitution & $\sigma_{c}$ & 1.500 \\
\hline Depreciation rate on capital & $\delta$ & 0.025 \\
\hline Capital share & $\alpha$ & 0.361 \\
\hline Steady-state gross markup & $\lambda$ & 1.100 \\
\hline Investment adjustment cost & $S$ & 10 \\
\hline Calvo parameter & $\theta$ & 0.750 \\
\hline \multicolumn{3}{|c|}{ Financial intermediation } \\
\hline Entrepreneur's survival probability & $\gamma$ & 97.620 \\
\hline Monitoring cost & $\mu$ & 0.200 \\
\hline Percent of bankrupt business $\mathrm{p} /$ quarter & $F\left(\omega^{\star}\right)$ & 0.750 \\
\hline Rental rate on capital (gross p/quarter) & $R^{k}$ & 1.015 \\
\hline Risk premium in annual percentage terms & $\frac{R^{k}}{R}$ & 2.080 \\
\hline \multicolumn{3}{|c|}{ Steady-state great ratios } \\
\hline Capital-output ratio & $\frac{k}{y}$ & 8.08 \\
\hline Investment-output ratio & $\frac{i}{y}$ & 0.2 \\
\hline \multicolumn{3}{|c|}{ Macroprudential policy } \\
\hline Steady-State reserve requirement & $\phi^{*}$ & 0.02 \\
\hline Sensitivity to credit growth & $\chi$ & 1.0064 \\
\hline \multicolumn{3}{|c|}{ Benchmark shock processes: Christiano et al. (2014) } \\
\hline $\mathrm{AR}(1)$ coefficients & $\rho_{a} ; \rho_{\sigma_{\omega}}$ & $0.81 ; 0.97$ \\
\hline Standard deviations & $\sigma_{\varepsilon_{a}} ; \sigma_{\varepsilon_{\sigma_{\omega}}}$ & $0.0046 ; 0.07$ \\
\hline
\end{tabular}


Table 2. Optimized Monetary Policy Rule

\begin{tabular}{c|cccccc}
\hline & \multicolumn{3}{|c}{ No Macroprudential Policy } & \multicolumn{3}{c}{ Optimized Macroprudential Policy } \\
Shocks & $g_{\pi}$ & $g_{y}$ & $g_{f}$ & $g_{\pi}$ & $g_{y}$ & $g_{f}$ \\
\hline TFP & 5.016 & 0 & 289.507 & 4.422 & 1.000 & 0.000 \\
Sigma & 28.243 & 0 & 125.490 & 1.398 & 0.000 & 0.000 \\
Sigma, TFP & 29.159 & 0 & 131.460 & 3.228 & 0.418 & 0.000 \\
\hline \hline
\end{tabular}


Table 3. Welfare Loss of Alternative Policy Rules

(Percent of Steady-State Consumption)

\begin{tabular}{lccc}
\multicolumn{1}{c}{ Monetary Policy Rules } & All & Phocks & \\
& & & \\
& & & \\
No Macroprudential Policy & 1.31 & 0.04 & 1.27 \\
Perfect Price Stability & 4.64 & 0.21 & 4.44 \\
Taylor Rule & & & \\
& & & \\
Macroprudential Policy $(\psi=3)$ & 0.03 & 0.004 & 0.03 \\
Perfect Price Stability & 1.52 & 0.78 & 0.75 \\
Taylor Rule & & & \\
& & & \\
Optimized Macroprudential Policy $(\psi=1.0064)$ & & & 0.06 \\
Perfect Price Stability & 0.11 & 0.04 & 0.41 \\
Taylor Rule & 0.74 & 0.33 & \\
\hline \hline
\end{tabular}



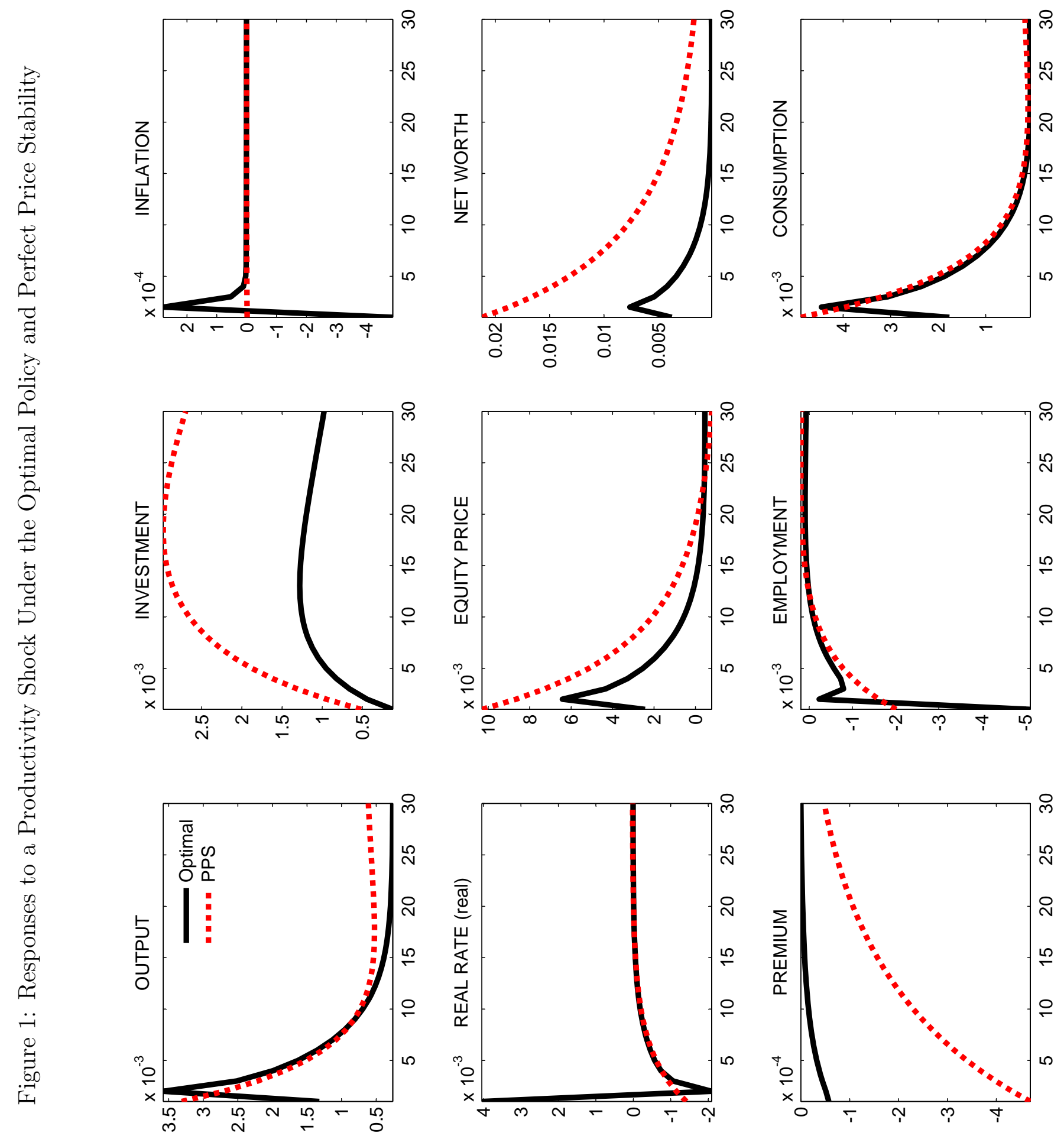
Figure 2: Responses to a Productivity Shock Under the Optimal Policy, Perfect Price Stability, and the Efficient Allocation
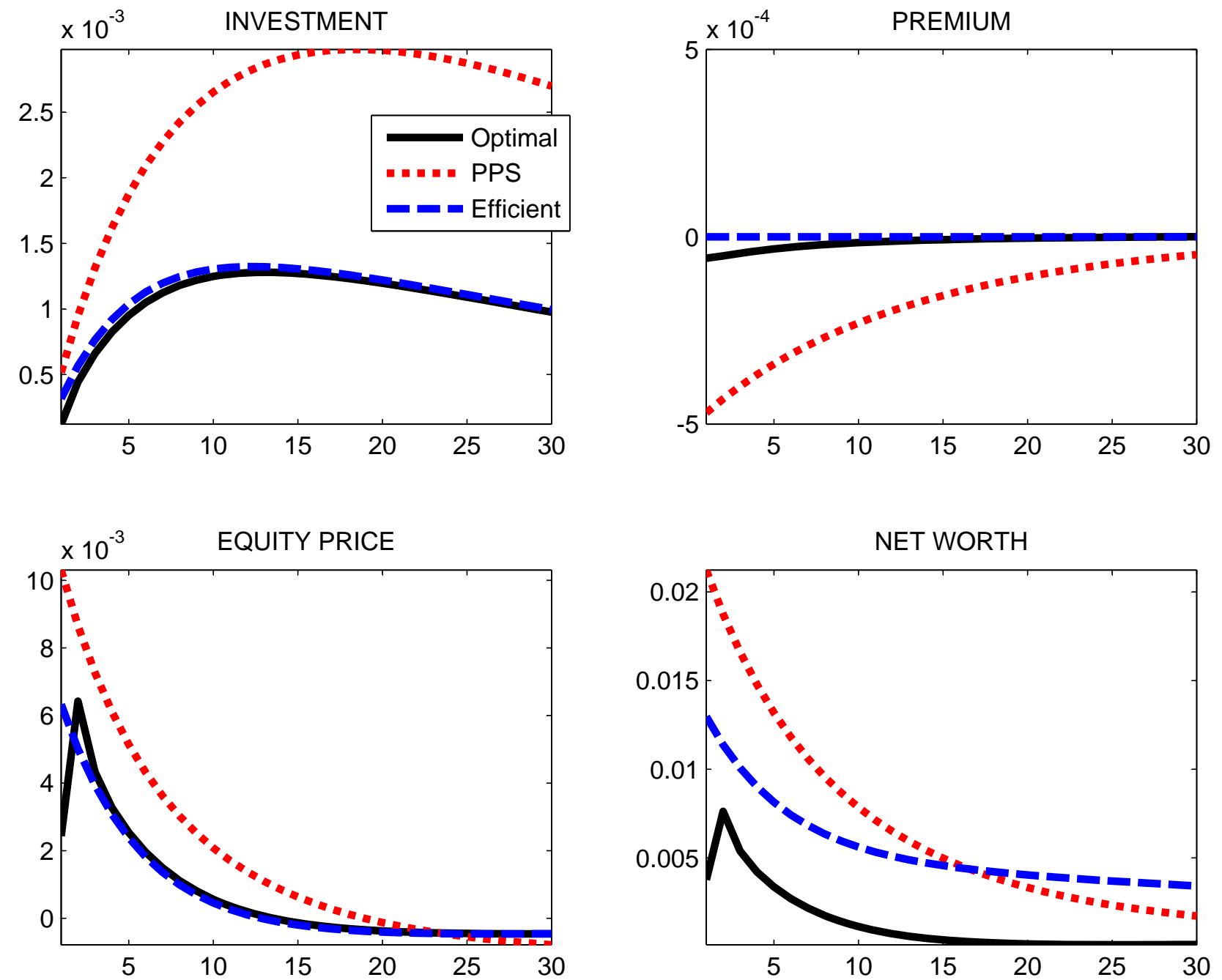


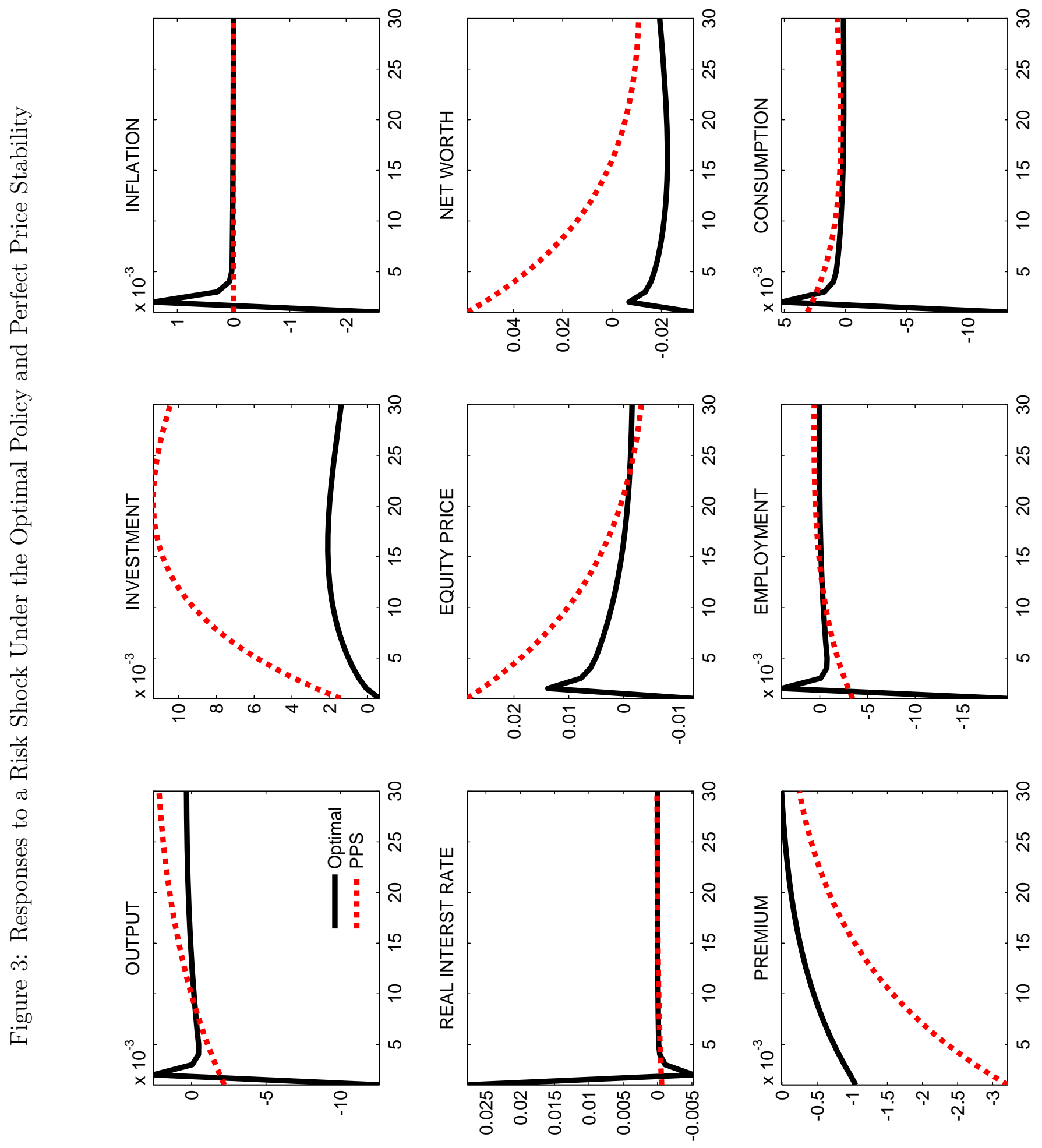


Figure 4: Responses Under the Optimal Policy and Perfect Price Stability: No Investment Adjustment Costs
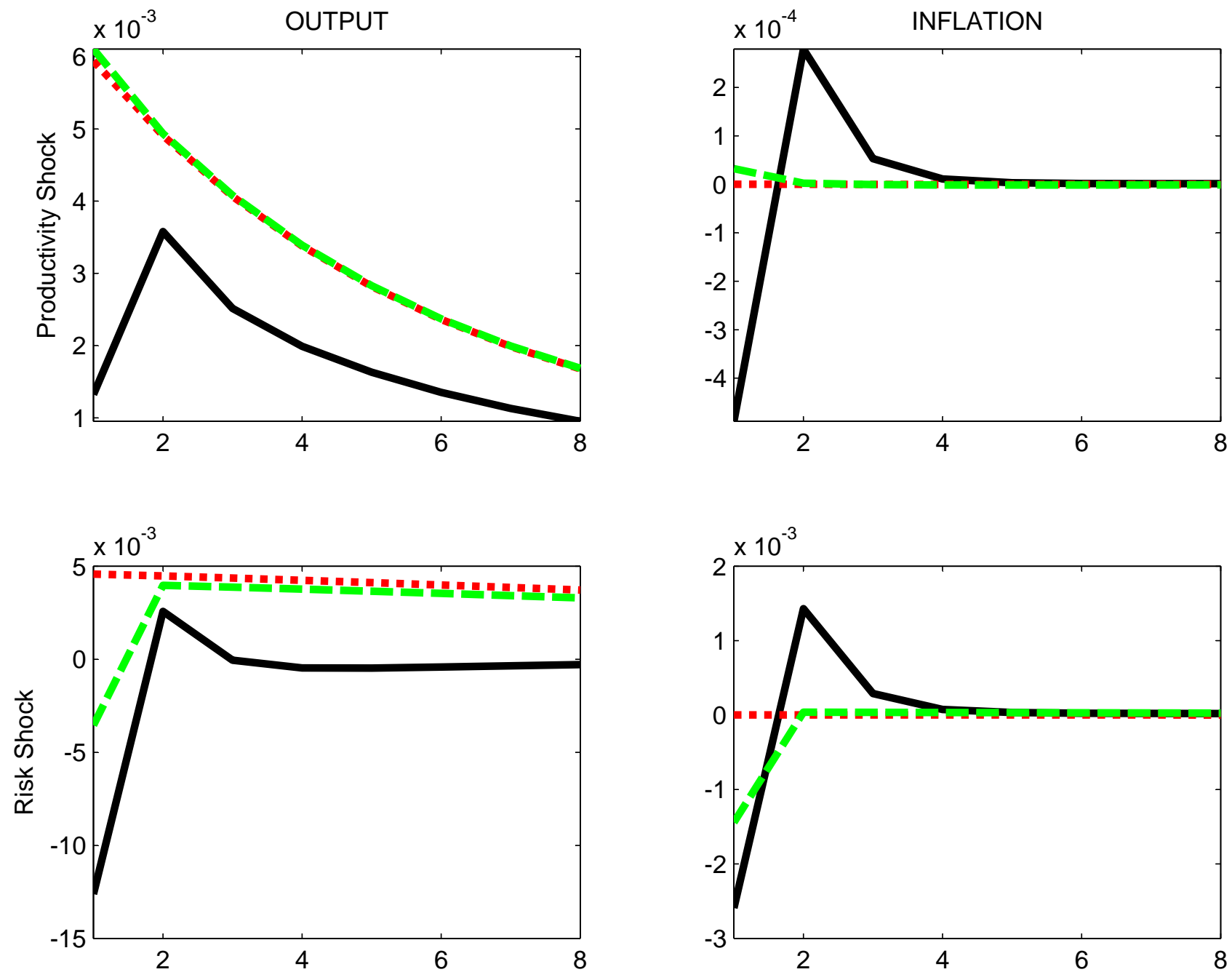

Opt. Policy with investment adj. costs

-..- PPS without investment adj. costs

$-=0$ Opt. Policy without investment adj. costs 
Figure 5: Optimal Policy Under Varying Degrees of the Financial Friction
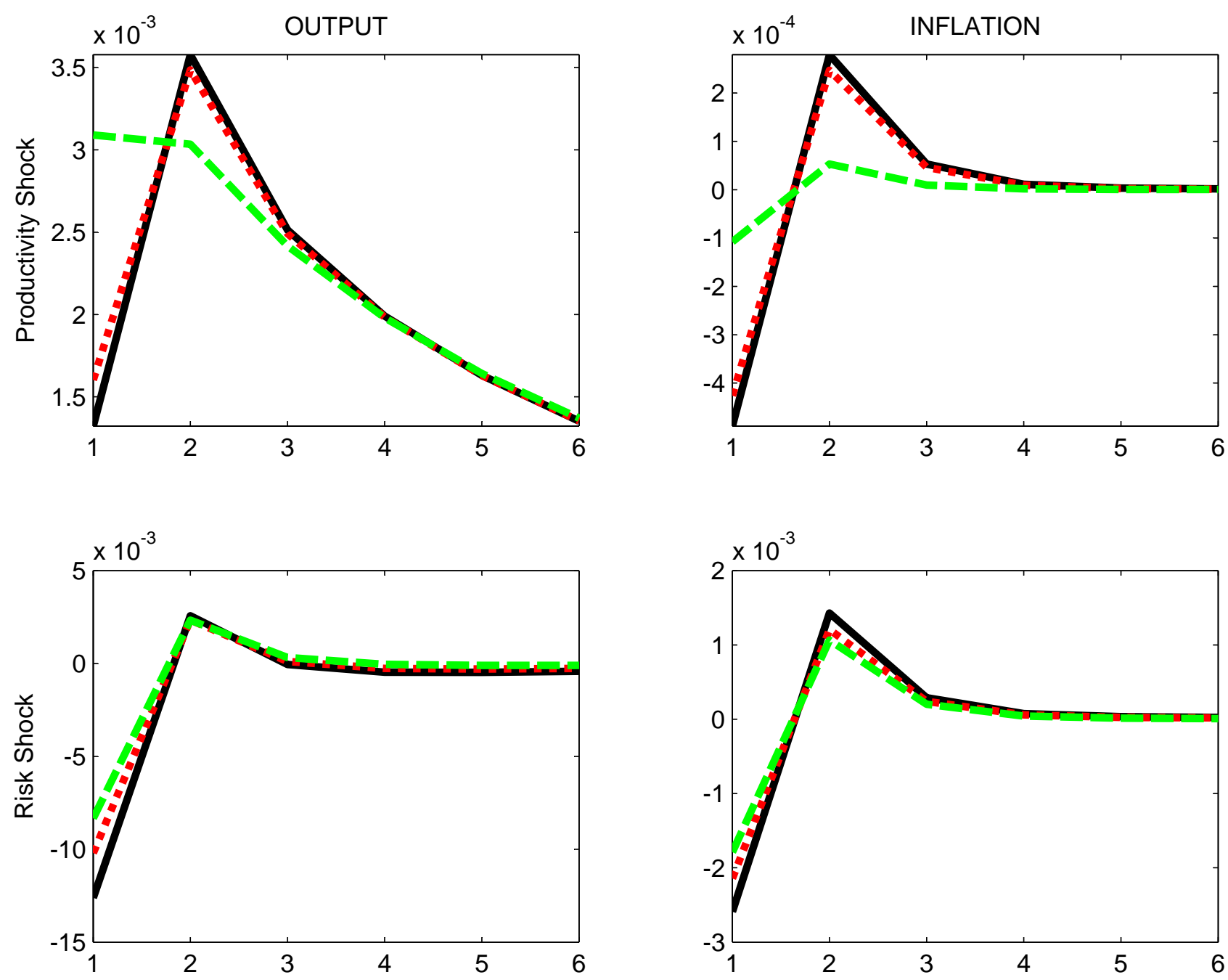

Optimal Policy: $\mu=0.2-0$ - Optimal Policy: $\mu=0.1-\infty$ 
Figure 6: Responses to Productivity and Financial Shocks: Subsidized Steady-State
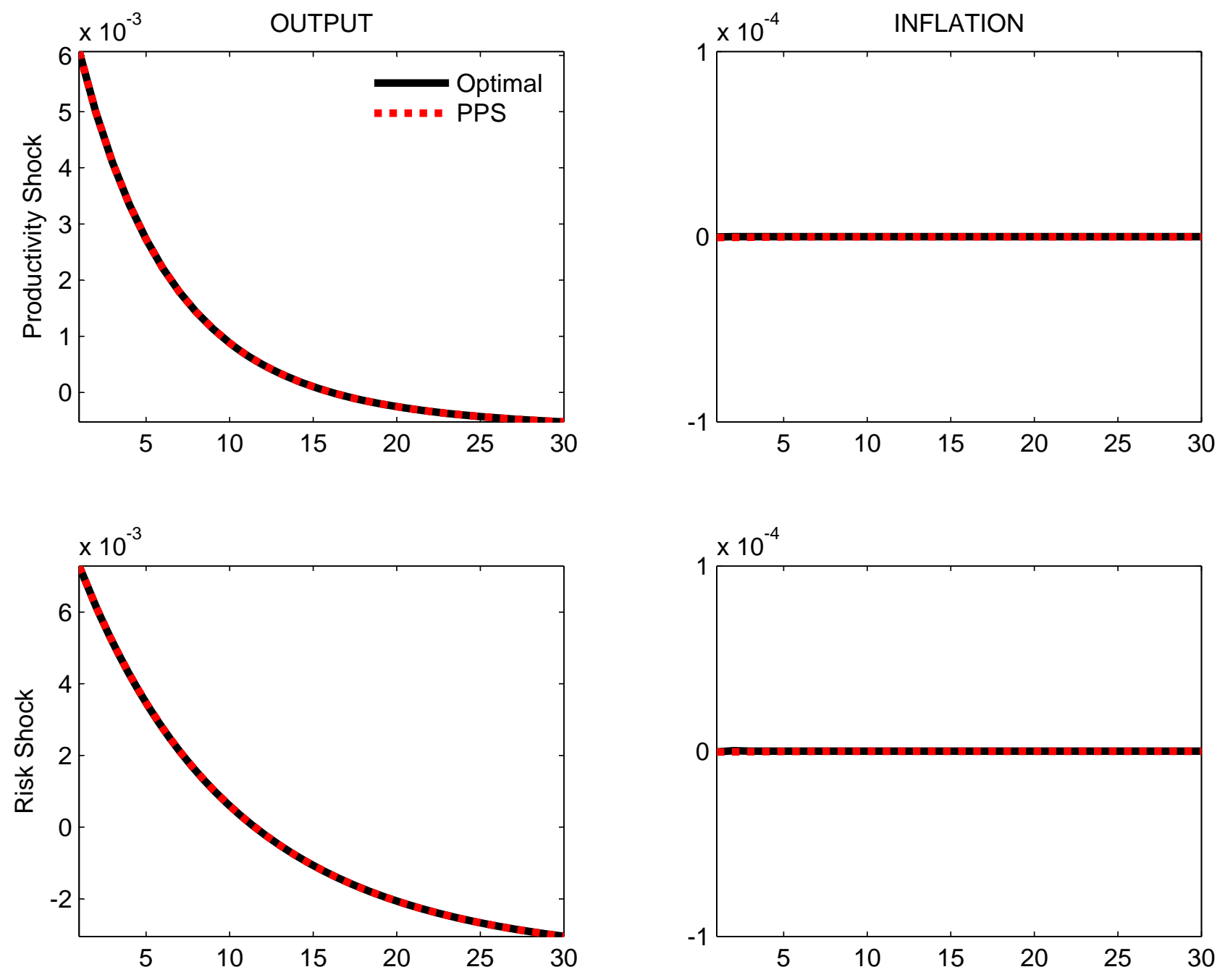
Figure 7: Output Wedge Responses to Productivity and Financial Shocks
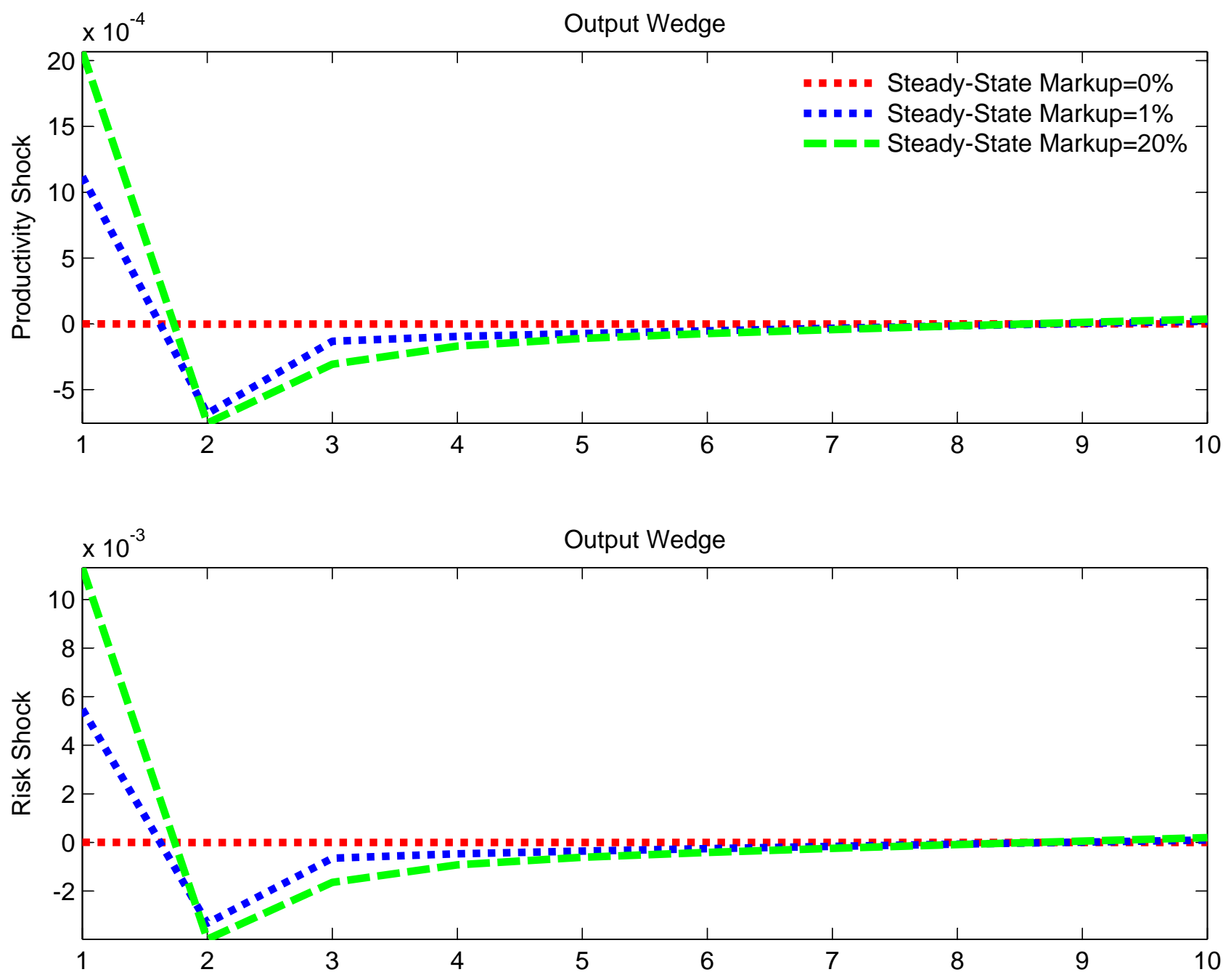


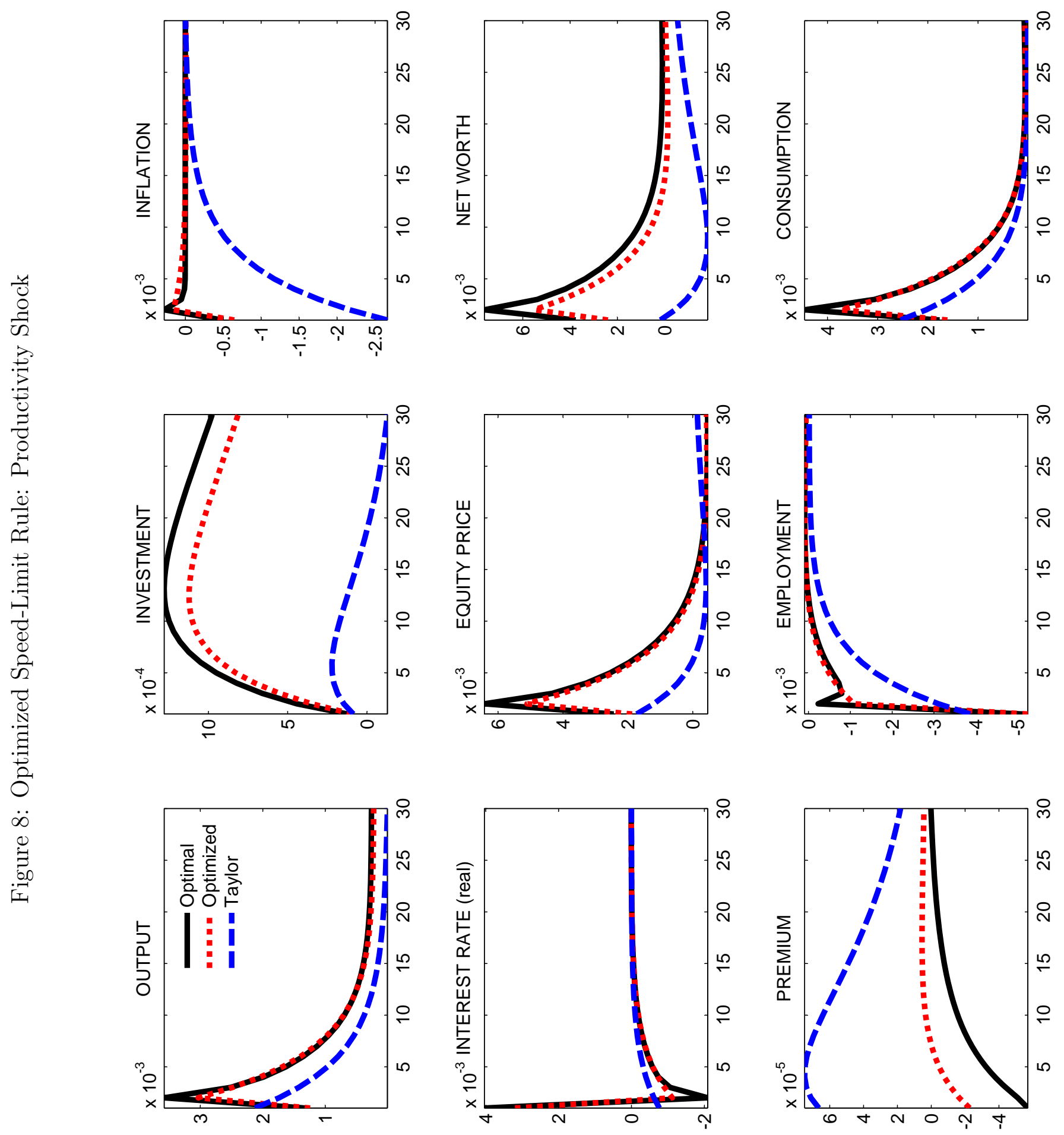




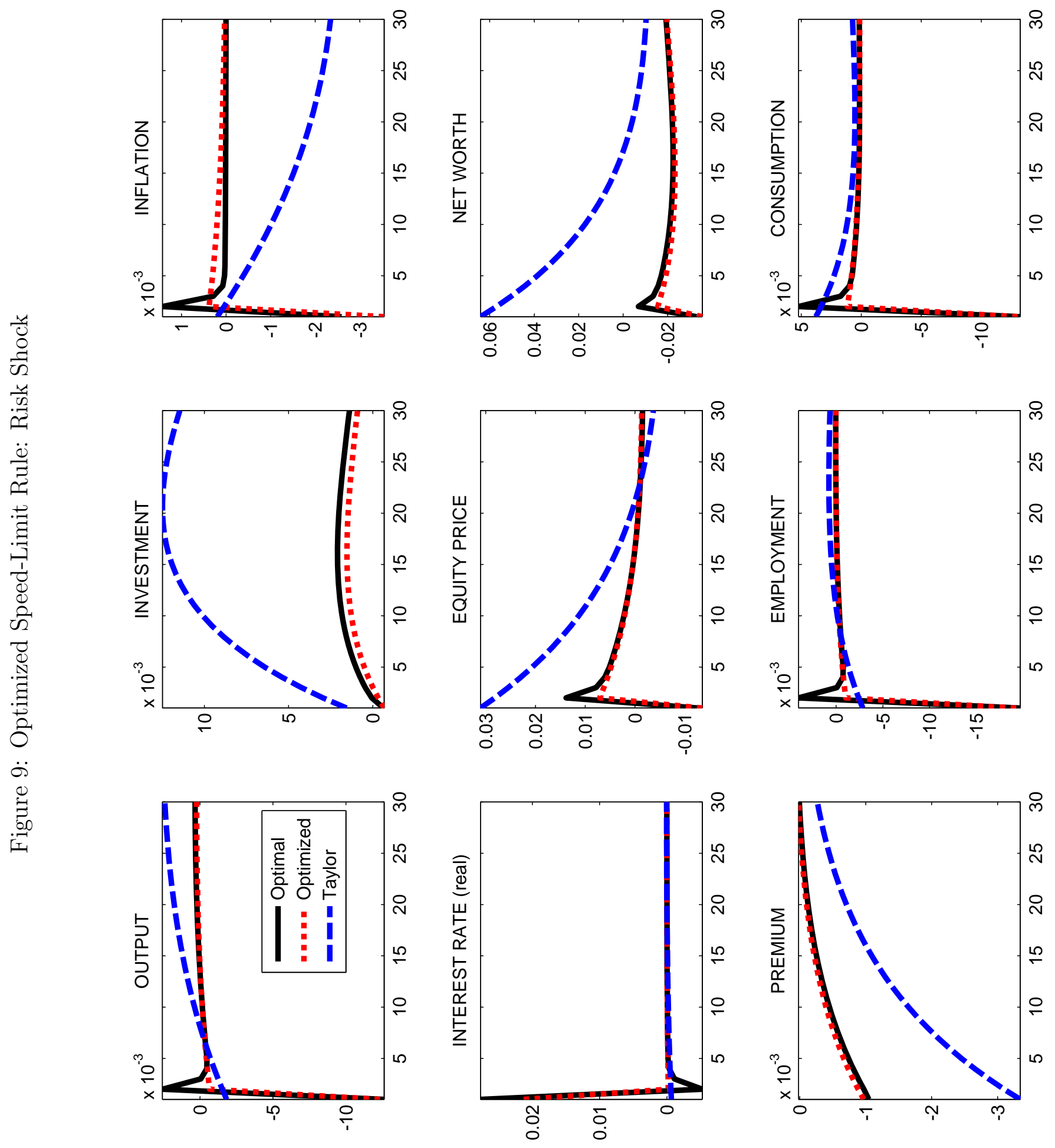



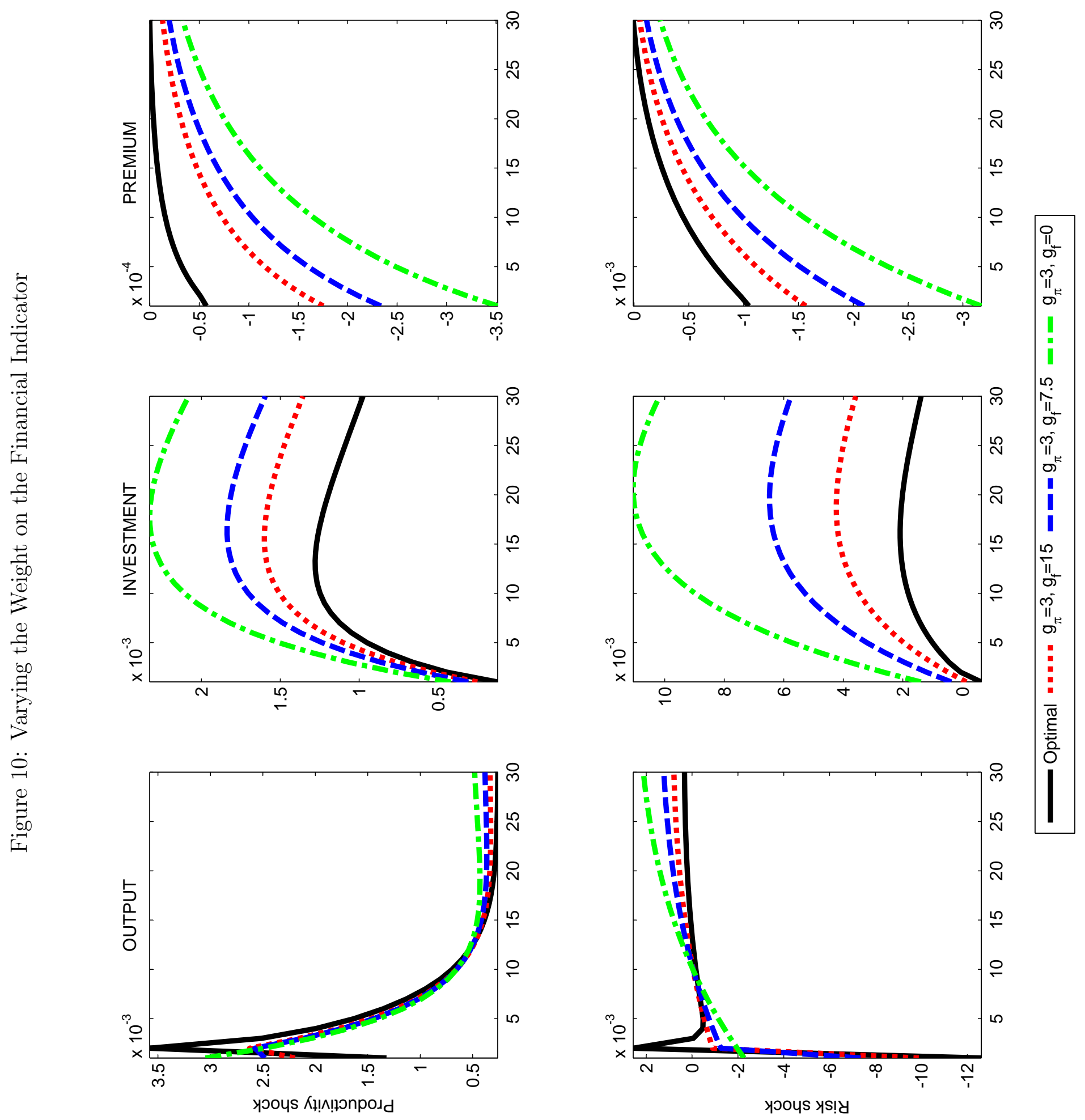


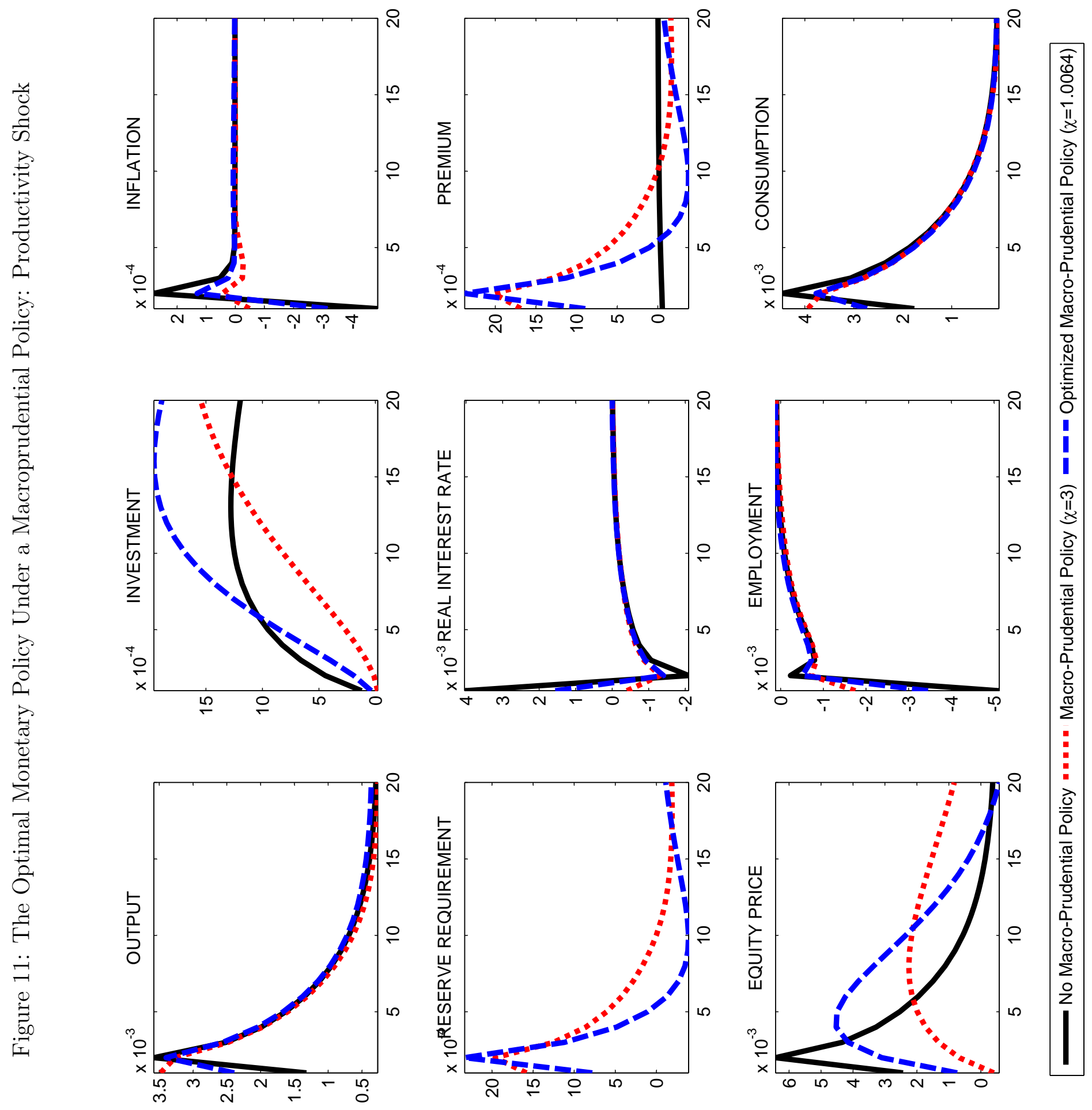




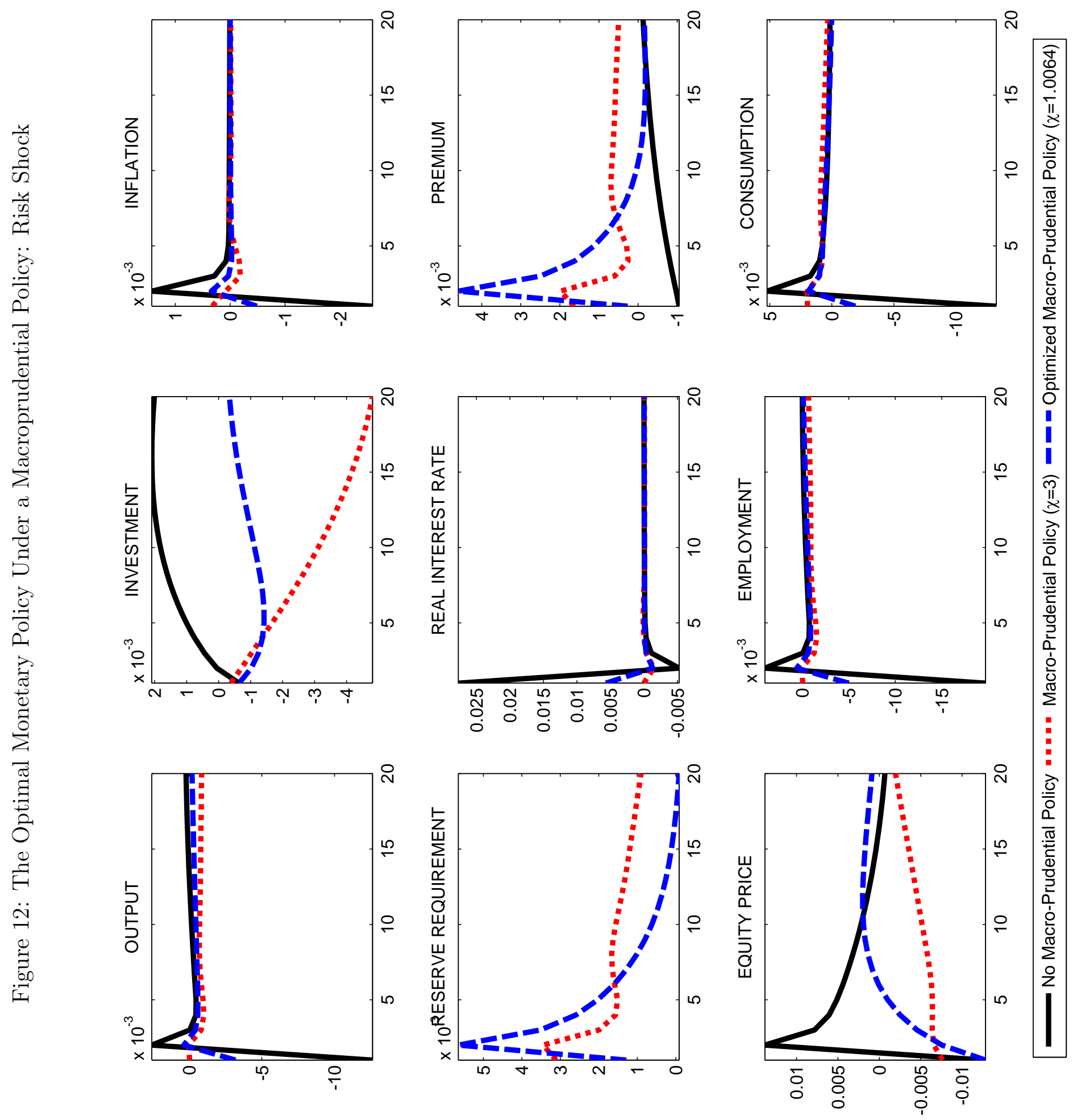

